Revista de Derecho

de la Pontificia Universidad Católica de Valparaíso

XXX (Valparaíso, Chile, $1^{\text {er }}$ Semestre de 2008)

[pp. $311-356]$

\title{
LA CODIFICACIÓN DEL DERECHO CANÓNICO DE 1917
}

[The Codification of the Canon Law of 1917]

\author{
Carlos Salinas Araneda* \\ Pontificia Universidad Católica de Valparaíso**
}

RESUMEN

Correspondió a san Pío X, poco después de haber sido elegido romano pontífice, iniciar la tarea de fijar el derecho canónico bajo la moderna forma de la codificación iusracionalista, trabajo que, iniciado en 1904, finalizó en 1917 cuando su sucesor, Benedicto XV, promulgó el Codex Iuris Canonici, el primero de los códigos de derecho canónico que ha habido en la Iglesia. Se estudian los antecedentes del proceso codificador, situados en el Concilio Vaticano I, el desarrollo de los trabajos codificadores y sus primeros efectos.

Palabras Clave: Codificación - Derecho canónico - Código de Derecho Canónico de 1917 - Fijación del derecho canónico.

\section{Abstract}

Shortly after being elected, Saint Pius $\mathrm{X}$ started working to set the canonic law under the modern form of the "ius-racionalist" codification. His work started in 1904 and finished in 1917 when his successor, Benedict XV, enacted the Iuris Canonici Codex, the first of the canon law codes the Church ever had. In this paper we study the background of the codification process, placed in the First Vatican Council, the development of the codification works and their first effects.

KeYwords: Codification - Canonic law - Code Canon Law of 1917 - Setting of canonic law.

* Profesor titular en la Facultad de Derecho de la Pontificia Universidad Católica de Valparaíso. Avenida Brasil 2950, Valparaíso, Chile. csalinas@ucv.cl. Este trabajo forma parte de la investigación FONDECYT 1070434 de la que el autor es investigador responsable.

** Abreviaturas: $A A S .=$ Acta Apostolicae Sedis; $A S S .=$ Acta Sanctae Sedis; ASV. CIC 17= Archivo Secreto Vaticano, Fondo Codificación del Derecho canónico 1917; m.p.= motu proprio; scat. $=$ cajeta; S.C. $=$ Sagrada Congregación; 
La Iglesia, fundada por Cristo al llegar la plenitud de los tiempos, tiene simultáneamente una dimensión divina y humana: es Cuerpo Místico de Cristo y, al mismo tiempo, en expresión de Pedro (1 Pe 2,9-10) nuevamente puesta de relieve por el Concilio Vaticano II (LG 9-17), es Pueblo de Dios. En esta dimensión societaria, la Iglesia, desde un comienzo, y como exigencia de su propia naturaleza, ha sentido la necesidad de configurarse como sociedad humanamente organizada tanto en su estructura jerárquica como en las relaciones interpersonales que se producen entre los fieles que la integran. El viejo principio ubi societas ibi ius no le ha sido ajeno y así, desde los primeros momentos, la Iglesia ha ido configurando un ordenamiento jurídico con clara conciencia de autonomía frente a los sistemas jurídicos seculares: el Derecho canónico.

Como Pueblo de Dios la Iglesia está inmersa en la historia de la cual el hombre es el sujeto por excelencia. Formada por hombres, sujeto de la historia, la Iglesia es, por lo mismo, histórica. Y lo es también su Derecho que, al ser, como todo Derecho, una de las expresiones del quehacer cultural del hombre, queda igualmente sometido al devenir histórico. Esta historicidad del Derecho de la Iglesia tiene una de sus expresiones no sólo en las diversas formulaciones que su contenido ha tenido a lo largo de los siglos, sino también en la forma externa de su fijación -recopilaciones, corpus, codex-. Es cierto que el Derecho canónico parte de un dato que le es dado, la revelación; hay todo un depósito de verdades, reveladas por el mismo Cristo, que nada ni nadie puede alterar. Pero es cierto también que la manera con que la Iglesia se ha enfrentado a esas verdades para profundizar más y más en ellas ha dependido de las diversas épocas históricas. Para ello la Iglesia, inmersa en la historia del hombre, ha usado de las categorías culturales propias de cada una de esas épocas. Su Derecho, así, no ha sido ajeno a esta realidad, y las distintas categorías que el Derecho canónico ha usado para regular, a partir de las verdades reveladas, la dimensión de justicia que existe entre los fieles que componen este Populus Dei, han dependido de cada momento histórico. Por eso el Derecho canónico no es inmutable en el tiempo y así como la cultura del hombre ha ido evolucionando, este Derecho también ha evolucionado.

El Derecho canónico, a lo largo de los siglos, ha mantenido una permanente relación con el Derecho de la sociedad civil, aunque no siempre con la misma intensidad; ha habido momentos de fuerte reciprocidad, como el ius commune bajo medieval; pero también de fuerte lejanía como en los siglos XIX y XX. En esta historia común, el Derecho canónico se ha visto influido más o menos intensamente por categorías jurídicas seculares de las que ha hecho uso para elaborar sus propias formulaciones. A la inversa, ha sabido dar su aporte original y enriquecedor al patrimonio 
jurídico común ${ }^{1}$ al punto que el Derecho canónico constituye, junto con el Derecho romano y el Derecho germánico, uno de los elementos que han configurado el Derecho occidental ${ }^{2}$.

\section{LOS ANTECEDENTES DE LA CODIFICACIÓN}

\section{Del "Corpus iuris canonici" al "Codex iuris canonici".}

El Derecho canónico constituye un elemento esencial de la Iglesia católica, razón por la cual las normas en la Iglesia han existido desde sus primeros momentos, en una evolución que ya alcanza los dos mil años. Durante el primer milenio dichas normas se recogieron en colecciones canónicas, de diversa naturaleza y contenido ${ }^{3}$, que fueron sustituidas en el segundo milenio con el Corpus Iuris Canonici, un amplio texto integrado por cinco colecciones, la primera de las cuales fue el Decreto de Graciano (1140) seguido por las Decretales de Gregorio IX (1234), el más importante de los textos canónicos de dicho Corpus. Lo integraban, además, el Liber sextus de Bonifacio VIII (1298); las Clementinas, una colección ordenada por el Papa Clemente V y promulgada en 1317 por su sucesor, Juan XXII; las Extravagantes comunes y las Extravagantes de Juan XXII, colecciones menores elaboradas en el siglo XVI por el jurista parisino Jean Chapius ${ }^{4}$.

En la medida que fue pasando el tiempo, junto al Corpus se fue elaborando una abundante legislación complementaria que venía a satisfacer las necesidades que iban originando las nuevas realidades históricas, de manera que, en pleno siglo XIX, el conocimiento del Derecho de la Iglesia

${ }^{1}$ Sólo a manera de ejemplo, Salinas Araneda, Carlos, El influjo del Derecho canónico en el Código Civil de la República de Chile (Valparaíso, Ediciones Universitarias de Valparaíso de la Pontificia Universidad Católica de Valparaíso, 2006).

${ }^{2}$ Gibert, Rafael, Elementos formativos del Derecho en Europa. Germánico, romano, canónico (Madrid, 1982).

${ }^{3}$ Para una historia del Derecho canónico en el primer milenio puede verse García y García, Antonio, Historia del Derecho canónico, I: El primer milenio (Salamanca, 1967), con abundante bibliografía hasta la fecha de su edición. Más recientemente, con la bibliografía posterior, EDwIN FERME, Brian, Introduzione alla storia delle font $i$ del diritto canonico, I: Il diritto antico fino al Decretum di Graciano (Roma, Pontificia Università Lateranense, 1998).

${ }^{4}$ El Corpus Iuris Canonici fue objeto de una edición oficial a cargo de una comisión romana cuyos miembros fueron llamados 'correctores romanos'. Fue instituida por san Pío V (1566-1572) y la edición de los correctores romanos publicada por Gregorio XIII (1572-1585) en 1582. Esta edición no recoge la denominación de Corpus Iuris Canonici, la que sí aparece en la edición de Lyon de 1671 y en las posteriores. La edición hoy utilizada habitualmente es la de A. E. Friedberg (Lipsiae 1879, Graz 1959). Con posterioridad el Corpus fue complementado incorporándose en diversas épocas otros elementos, algunos de los cuales sólo en ediciones privadas. 
se hacía en extremo difícil, con la consecuente dificultad en su aplicación y la secuela de inobservancia que un tal fenómeno trae consigo. El Corpus, cuyos textos se habían originado en el medioevo, ya no satisfacía a los hombres del siglo XIX, y no sólo el Corpus, sino que incluso las decisiones tomadas por las Congregaciones romanas anteriores a la Revolución Francesa. Un postulatum de once obispos franceses durante el Concilio Vaticano I (1869-1870) resulta en este sentido revelador": "Es una cosa muy evidente y reconocida desde hace mucho tiempo por todos y por todas partes reclamada que es necesario y muy urgente un examen y una refundición del Derecho canónico. Porque, como consecuencia de los grandes y numerosos cambios sobrevenidos en las circunstancias y en la sociedad humana, muchas leyes han llegado a ser inútiles o inaplicables o muy difíciles de observar. Se duda, incluso, si numerosos cánones se encuentran aún en vigencia. En fin, a lo largo de tantos siglos el número de leyes eclesiásticas ha crecido de tal manera y ellas forman un tal cúmulo de colecciones que, en cierto sentido, podemos decir que estamos aplastados por las leyes. Como consecuencia de esto el estudio del Derecho canónico está lleno de dificultades inextricables y casi infinitas; el más vasto campo está abierto a las controversias y procesos; las conciencias están oprimidas por miles de angustias y empujadas al menosprecio de la ley".

Quejas a las que se unían los obispos napolitanos ${ }^{6}$, en especial en lo referido a la masa de leyes existente: "la colección concreta de nuestros cánones sería tan pesada, que un camello tendría dificultades para transportarla. De donde se sigue que, sobre muchos puntos, se pueden sostener muy bien el pro y el contra, y textos se citan y textos se objetan, decisiones y sentencias en cualquier sentido, con lo que jamás las controversias pueden ser dirimidas. Esto no es digno de la Iglesia que debe volver a ser lo que era antańo: un modelo y una luz para los otros legisladores”.

Haciéndose eco de estas quejas, uno de los primeros manuales surgidos después de la promulgación del Código de Derecho Canónico ilustraba así el problema de las fuentes canónicas pre-codiciales?: "Hasta la aparición del Código, para tener todas las fuentes jurídicas era necesario poseer el Corpus Iuris, el Tridentino, los Bularios, que constan de muchos tomos en folio y son incompletos y de difícil adquisición; las colecciones auténticas de las SS. CC. De Ritos (cinco tomos) y de Indulgencias (un tomo), el Thesaurus

${ }^{5}$ Mansi, J. D., Sacrorum conciliorum nova et amplissima collectio, Sacrosancti Oecumenici Concilii Vaticani, 53, col. 331-352, esp. 341-342.

${ }^{6}$ Ibíd., col. 552-553.

${ }^{7}$ Ferreres, Juan B., sj., Instituciones canónicas con arreglo al novísimo código de Pio X promulgado por Benedicto XV y a las prescripciones de la disciplina española (Barcelona, 1917), pp. 30-31. 
Resol. S. C. C. (ciento sesenta y tantos tomos, muchos de ellos en folio), etc., y añadir a éstas muchas otras colecciones privadas. De modo que no sin razón se decía que el Derecho canónico era "onus multorum camelorum". Con esto se ve cuán difícil se hacía consultar las fuentes del Derecho, y cuán ardua era su aplicación en los tribunales, pudiéndose alegar en pro y en contra de unas mismas cuestiones disposiciones legales vigentes". La consecuencia no podía ser sino el quebranto de la disciplina en la vida eclesial, el mayor arbitrio de los órganos ejecutivos, la incertidumbre en las decisiones de los tribunales que tendían a fundamentar la sentencia en la conciencia del juez, la inseguridad de las relaciones especialmente en el ámbito diocesano en el que se dependía más del arbitrio del obispo que de los cánones sagrados, y la despreocupación entre el clero por los estudios canónicos ${ }^{8}$.

El problema no sólo se vivía con el Derecho de la Iglesia, pues con el Derecho de los Estados se había producido un fenómeno similar que exigió una respuesta creadora, la que vino de la mano de la codificación iusracionalista. El siglo XIX fue el marco cronológico en que vieron la luz los más importantes códigos producidos por la última de las formas de fijación del Derecho que hasta el momento se ha producido. Nacida en el siglo XVI, los primeros códigos aparecieron en la segunda mitad del siglo XVIII, consolidándose como forma fijadora con el Código Civil de Napoleón (1804) y el Código austriaco (1811) ${ }^{9}$. A partir de entonces y a lo largo de todo el siglo los códigos empezaron a multiplicarse ${ }^{10}$. Diversos elementos configuraron el movimiento codificador, que Guzmán ${ }^{11}$ ha sintetizado en: i) una filosofía: el iusnaturalismo racionalista; ii) un material de Derecho al cual dicha filosofía se aplicó: el Derecho romano iusnaturalista; y iii) una forma de presentar el resultado de esa síntesis filosófico-jurídica: el sistema axiomático de tipo matemático.

El éxito de la codificación expresado en la acogida que tuvieron los có-

${ }^{8}$ Motilla, Agustín, La idea de codificación en el proceso de formación del Codex de 1917, en Ius Canonicum 28 (1988), 56, pp. 684-685.

${ }^{9}$ Una reciente y completa síntesis sobre la codificación en GuzMán Brito, Alejandro, El origen y desarrollo de la idea de codificación del Derecho, en GuZMán BRITo, Alejandro (ed.), El Código Civil de Chile (1855-2005). Trabajos expuestos en el Congreso internacional celebrado para conmemorar su promulgación (Santiago, 3-6 de octubre de 2005) (Santiago, LexisNexis, 2007), pp. 43-99.

${ }^{10}$ En Chile el Código Civil, uno de los mejores códigos decimonónicos, fue promulgado en 1855, iniciándose un proceso codificador que, pasando por los códigos de comercio (1865) y penal (1874), culminó a principios del siglo XX con los de procedimiento civil (1902) y procedimiento penal (1906).

${ }^{11}$ Guzmán Brito, Alejandro, La fijación del Derecho (Valparaíso, 1977), pp. 53-90. 
digos iusracionalistas fue indudable. Y no podía ser menos: como el mismo Guzmán ${ }^{12}$ ha señalado, "dejando a un lado todos los aspectos propiamente filosóficos y materiales, a los cuales ese éxito se vincula específicamente, un Derecho que se presentaba con el ropaje de la lógica y de las matemáticas, a partir de definiciones y desarrollado en proposiciones concatenadas, tenía que mostrarse como superior a un Derecho fragmentario, casuístico, empírico, atiborrado de opiniones y pareceres, basado en la discusión dialéctica, como era el Derecho romano común y el propio de cada país. Certeza, claridad, fijeza, eran ideales que la forma de concebir el Derecho alcanzada por los iusnaturalistas satisfacían plenamente".

El éxito que había tenido la codificación en los Derechos estatales no podía pasar desapercibido a los juristas de la Iglesia quienes hicieron oír su voz en el Concilio Vaticano I, donde, empero, las soluciones que se propusieron en orden a la fijación del Derecho de la Iglesia no fueron coincidentes $^{13}$.

\section{El Concilio Vaticano $I$.}

El 6 de diciembre de 1864 el Papa Pío IX se reunió en el Vaticano con un grupo de cardenales a quienes manifestó su intención de reunir un concilio ecuménico a fin de proveer con este medio extraordinario a las necesidades extraordinarias de la Iglesia. Les pidió reflexionar con seriedad acerca del proyecto y que le hicieran llegar por escrito, personalmente, sus consideraciones. La mayor parte de los cardenales respondieron que era de utilidad adaptar la legislación eclesiástica a los tiempos presentes, a pesar de la dificultad de la empresa.

En la alocución consistorial dada en la fiesta del centenario del martirio de san Pedro (1867) el Papa anunció oficialmente el próximo concilio. Se

${ }^{12}$ Ibíd., p. 79.

${ }^{13}$ En relación con el debate antecedente a la codificación canónica, puede consultarse: Anónimo, Pio X e la codificazione del diritto canonico, en Il contencioso ecclesiastico 5 (1904), pp. 66-68; BersANI, F., Le fonti del diritto canonico prima della codificazione, en Rivista di diritto ecclesiastico 10 (1917), pp. 23-41; Boudinhon, A., De la codification du droit canonique, en Le canoniste contemporain 27 (1904), pp. 641-650; 28 (1905), pp. 18-23, 76-83, 139-149, 207-215, 302-309, 473-481, 563568; Calisse, C., La codificazione del diritto canonico, en Rivista internazionale di scienze sociali 35 (1904), pp. 346-365; LAMER, H., Zur Codification des canonischen Rechts (Freiburg Br., 1899), pp. 63-96; 212-213; Rufini, Francesco, La codificazione del diritto ecclesiastico, en AA. VV., Studi di diritto in onore di Vittorio Scialoja (Milano, 1905), II, pp. 353-391; Villien, A., Les reformes du droit canonique et les postulata du concile du Vaticain, en Le canoniste contemporaine 29 (1906), pp. 65-74, 209-221, 369-384, 449-463, 554-564, 652-659, 712-717; 30 (1907), pp. 74-83, 137-147, 220-228, 273-283; 31 (1908), pp. 16-23, 207-219, 364-376. 
organizaron cinco comisiones de consultores ${ }^{14}$ cuyo trabajo desembocó en los esquemas disciplinares que debían ser presentados a los padres conciliares $^{15}$. Iniciado el Concilio el año 1869, estos esquemas fueron distribuidos a los padres conciliares, pero de ellos sólo cuatro fueron discutidos, pues, a la lentitud de las discusiones que se dieron en el aula conciliar, se agregaron las dificultades políticas originadas por la guerra de unificación de Italia que llevaron a la invasión de los Estados Pontificios y a la clausura adelantada del concilio en 1870 . Con todo, y no obstante que la mayor parte de ellos quedaron como proyectos, fueron importantes para los canonistas. De hecho, sirvieron a los sucesores de Pío IX para legislar sobre aspectos particulares de la disciplina de la Iglesia, introduciendo las reformas oportunas; y constituyeron la base del Código de 1917.

El Concilio no tocó directamente el tema de la codificación del Derecho canónico, pero antes y durante él se escucharon voces que pedían una solución a tal estado de $\operatorname{cosas}^{16}$, con proposiciones que sugerían modalidades diversas que Motilla ${ }^{17}$ ha sintetizado de la siguiente manera: i) una nueva y profunda r evis i ó n del Corpus iuris canonici con el fin de eliminar las normas derogadas; ii) la elaboración de una c o le c ción of i c i a l, compuesta funda-

${ }^{14}$ Comisión de la doctrina, de la disciplina, de los religiosos, de las iglesias orientales y misiones, y de asuntos político eclesiásticos. La comisión de la disciplina estaba encargada de reunir y clasificar metódicamente las prescripciones del Concilio de Trento, las actas de la Santa Sede y los decretos de las Congregaciones romanas. Además, debía preocuparse de las costumbres que se habían introducido, los usos que habían prevalecido y las costumbres locales. En su trabajo fueron de utilidad, igualmente, las respuestas dadas por los obispos consultados por Pío IX entre 1865 y 1867 y las actuales necesidades de la Iglesia.

${ }^{15}$ Fueron 28 esquemas en los que se exponían los puntos más importantes del Derecho canónico y de la moral cristiana: las leyes de la Iglesia concernientes a los obispos, los vicarios generales, los concilios provinciales, los sínodos diocesanos, los capítulos, los curas y las parroquias, los clérigos y los seminarios, la predicación, la enseñanza catequística y la administración de los sacramentos, los impedimentos del matrimonio, los matrimonios mixtos y los matrimonios civiles, la reforma de las costumbres por la lucha contra los principales males de la sociedad moderna, la santificación de los domingos y de las fiestas, los ayunos y las abstinencias, el duelo y el suicidio, el magnetismo, espiritismo y las sociedades secretas. En fin, un abanico extenso de materias que fueron una vez más examinadas, fijadas y prudentemente adaptadas a los tiempos modernos.

${ }^{16}$ Fueron los postulados suscritos por 37 obispos napolitanos, en MAnsi, J. D., Sacrorum conciliorum nova et amplissima collectio, Sacrosancti Oecumenici Concilii Vaticani, 53, col. 378-456, esp. 449-450; 11 obispos franceses, ibíd., col. 331-352, esp. 341-342; 15 obispos alemanes, ibíd., col. 352-378, esp. 355; el episcopado belga, ibíd., col. 456-461, esp. 460-461; 33 padres de diversas naciones, ibíd., col. 478479; los obispos de las provincias eclesiásticas de Québec y Halifax, ibíd., col. 467; y un grupo de prelados de Italia central, ibíd., col. 552-553.

${ }^{17}$ Motilla, Agustín, cit. (n. 8), pp. 685-686. 
mentalmente por el ius novissimum del concilio de Trento y las disposiciones del propio concilio Vaticano I, que se añadirían al Corpus a modo de Liber septimus; iii) la creación de un nuevo Corpus iuris canonici con todas las leyes vigentes de la Iglesia católica cuyas materias tuvieran verdadera trascendencia en la actualidad eclesial de la época. Esta nueva colección sustituiría al viejo Corpus como fuente principal del ordenamiento canónico; iv) abandonar el método de las colecciones y adaptar a la legislación canónica la técnica de la co difica ción desarrollada en los Estados, pero únicamente para aquellas materias que requieren con urgencia normas ciertas y bien definidas, como son los supuestos del Derecho procesal y penal canónico; v) llevar a cabo una ordenación íntegra del Derecho canónico a través de su completa co difi c a ción, de tal manera que se elabore un único texto distribuido, como los códigos estatales, en títulos, capítulos y parágrafos, que expongan de manera clara y precisa las disposiciones del legislador y sea la fuente legal de exclusiva aplicación.

De esta manera, las alternativas fijadoras que estaban en juego eran dos: continuar con la vieja modalidad de las colecciones sistemáticas, al estilo del Corpus iuris canonici vigente; o adoptar derechamente la moderna forma fijadora de la codificación. Hay que tener presente, sin embargo, que la terminología es usada libremente por los obispos, de manera que es preciso estar al contenido de la propuesta para entender la modalidad fijadora sugerida. Son los postulados de los obispos franceses, belgas y de las provincias eclesiásticas de Québec y Halifax los que más claramente se definen por la adopción para la Iglesia de un código al estilo de los códigos estatales ${ }^{18}$, utilizando argumentos eminentemente prácticos, sin plantearse en profundidad la compatibilidad entre esta nueva modalidad fijadora del Derecho de los Estados y las peculiaridades del ordenamiento canónico, ni los efectos que podrían traer para la Iglesia la adopción de la misma. De hecho, "no existe rastro de condena entre los padres conciliares a los principios teóricos de la codificación estatal, aquellos derivados del racionalismo y el utilitarismo de la Escuela del Derecho natural y el movimiento de la Ilustración, que chocaban irremediablemente con la doctrina filosófica y jurídica de la Iglesia" 19 .

Quienes postulaban sólo la revisión del Corpus, conservando la fijación del Derecho de la Iglesia en la forma de colecciones, tampoco lo hacían por una crítica a los efectos que la adopción de las codificaciones estatales pudiera traer al Derecho canónico; "las razones aducidas se fundamentan más en

${ }^{18}$ No deja de llamar la atención que estos últimos prelados, pertenecientes en su mayoría al mundo cultural del Common Law, propongan la codificación típica del Derecho continental. Motilla, Agustín, cit. (n. 8), p. 693.

${ }^{19}$ Motilla, Agustín, cit. (n. 8), p. 695. 
una difusa inercia histórica que en análisis críticos sobre posibles efectos del método codificador en el Derecho de la Iglesia. Simplemente, no se ven las ventajas que aporta el sistema de codificación respecto al de colecciones" ${ }^{20}$.

La discusión, sin embargo, no era baladí, pues uno de los efectos de la codificación canónica más resaltado y comentado por la doctrina moderna ha sido el de la centralización y afianzamiento del poder del Romano pontífice en detrimento de la autonomía legislativa de las iglesias particulares. "La técnica codificadora sirve, así, como instrumento utilizado por la Santa Sede en una época que, por circunstancias políticas y eclesiales, necesita acrecentar su poder" 21 .

Las diversas proposiciones presentadas al concilio no llegaron a ningún resultado, pues debió ser suspendido por el Papa como consecuencia de los sucesos políticos originados por las guerras de unificación del reino de Italia y la invasión de los Estados Pontificios por parte de las tropas monárquicas.

\section{Los años siguientes al concilio.}

La documentación recogida para el concilio había abordado prácticamente todas las materias canónicas y había sido tratada por prelados de formación intelectual diversa, de países diferentes, de tendencias divergentes y de valor desigual. Pero formaba un conjunto original y una rica documentación que el Papa León XIII y el mismo san Pío X utilizaron para establecer sus principales reformas ${ }^{22}$.

Por su parte, la doctrina se manifestó crítica al estado que presentaba el Derecho canónico en sus fuentes, haciéndose eco de los planteamientos episcopales hechos en el concilio, pidiendo una reforma que era cada vez más urgente. Así, por ejemplo, para Manjón ${ }^{23}$, "cuantos tratadistas tocan

${ }^{20}$ Ibíd., p. 694.

${ }^{21}$ Motilla, Agustín, cit. (n. 8), p. 695. A nivel de los Estados no hay que olvidar que la codificación facilitó el desequilibrio de las fuentes del Derecho a favor del dogma de la soberanía de la ley, sometiendo la costumbre y la jurisprudencia; y contribuyó a acrecentar la centralización del poder que caracteriza al Estado moderno.

${ }^{22}$ De la legislación producida por León XIII, que, en el fondo, es un precedente parcial de la codificación que se preparaba, se puede citar la constitución Officiorum ac munerum, de 25 de enero de 1897, codificando y dulcificando las leyes relativas a la prohibición y censura de libros; la constitución Conditae a Christo, de 8 de octubre de 1900, dando un estatuto legal preciso a las congregaciones religiosas de votos simples; la instrucción de la Congregación de los obispos y religiosos, del 11 de junio de 1880 , estableciendo un nuevo procedimiento en materia de causas disciplinares y criminales de los clérigos.

${ }^{23}$ Manjón, Andrés, Derecho eclesiástico general y español (Granada, 1884), I, n. 431. 
este punto están conformes en la necesidad de una nueva colección auténtica; varios Padres lo pidieron así en el Concilio del Vaticano; y el escritor cristiano que anhela ver el Derecho de la Iglesia más y más conocido para que sea mejor practicado y más amado por todos los hombres de recta voluntad, no puede menos de suspirar por que el cielo nos envíe siquiera un San Raimundo de Peñafort, apoyando a un Gregorio IX ${ }^{24}$. Del Derecho eclesiástico ${ }^{25}$ se puede decir lo que se dijo en otro tiempo gráficamente del Derecho romano: "est onus multorum camelorum" [= "es carga de muchos camellos"]. En términos parecidos se manifestaban otros autores como Pillet $^{26}$ o Lega $^{27}$; y las mismas ideas eran expuestas en la memoria De la codification du droit canonique presentada al Congreso internacional de Friburgo, Suiza en $1897^{28}$.

La idea de codificar el Derecho canónico según la moderna técnica codificadora utilizada por los Estados, sin embargo, no fue recibida con unánime entusiasmo. Se le criticaba, por una parte, que los presupuestos filosóficos e ideológicos que animaban las codificaciones seculares no eran siempre conciliables con el mensaje evangélico y aceptar la codificación, necesariamente implicaba aceptar dichos presupuestos. Por otra parte, la masa de fuentes existentes y el confuso estado en que se encontraban, se decía, hacían prácticamente imposible una empresa tal.

La realidad se encargó de mostrar que estas críticas carecían de fundamento. De hecho, a partir de 1811 con la aparición del Allgemeines Bügerliches Gesetzbuch austriaco -Código civil austriaco- la codificación tendió a "dejar de ser un problema de ideología para transformarse en una solución técnica, definitivamente recibida y adquirida, independiente de los supuestos espirituales que la habían originado: pasa a ser una manera de presentar lo jurídico considerada técnicamente superior" ${ }^{29}$. Por su parte, no faltaron los intentos

${ }^{24}$ San Raimundo de Peñafort (1175-1275) fue el fraile dominico a quien el Papa Gregorio IX (1227-1241) encomendó la confección de las Decretales (1140), la segunda colección de cánones del Corpus Iuris Canonici, la más famosa colección canónica del segundo milenio, sobre la cual se volcaron los afanes intelectuales de los mejores canonistas del milenio.

${ }^{25}$ Esta denominación era aplicada en el siglo XIX al Derecho canónico. Actualmente tiene un significado preciso: el Derecho de los Estados (por ende, no es Derecho canónico, sino estatal) regulador del hecho religioso como factor social.

${ }^{26}$ Pillet, Albert, Ius canonicum generale distributum in articulos (Parisiis, 1890), p. V.

${ }^{27}$ LegA, Michael, De iudiciis ecclesiasticis (Roma, 1896), I, Proëm., p. 9.

${ }^{28}$ Compte rendú, Quatrieme section, p. 319 ss. La cita es de Ferreres, Juan B., sj., Instituciones canónicas con arreglo al novísimo código de Pío X promulgado por Benedicto XV y a las prescripciones de la disciplina española (Barcelona, 1917), p. 32.

${ }^{29}$ Guzmán, La fijación, cit. (n. 11), p. 54. 
prácticos hechos por canonistas particulares que presentaron en forma de código moderno materias del Derecho canónico vigente como una manera de probar que la codificación del Derecho de la Iglesia no era tarea imposible; se trató de iniciativas privadas que no siempre tuvieron la misma trascenden$\mathrm{cia}^{30}$. Destacaron Florent Deshayes $(+1930)^{31}$, Alberto Pillet ${ }^{32}$, Emmanuel Colomiatti ${ }^{33}$ y Enrico Maria Pezzani ${ }^{34}$, entre los ensayos de carácter general y José Cadena y Eleta $(+1918)^{35}$ y George Peries $(+1934)^{36}$ entre los intentos

${ }^{30} \mathrm{El}$ primero de todos, que tuvo escasa relevancia por sus deficiencias, fue el de DE LuISE, Gaspard, Codex canonum Ecclesiae qui ex antiquo jure adhue usque vigent et ex concilii Tridentini decretis pro clero atque populi christiani reformatione editis diligenter deprompti atque ex summorum pontificum nuperque Pii IX tam per se quam in sacro concilio Vaticano constitutionibus excripti traduntur concinnatus (Napoli, 1873). Los defectos de este trabajo eran comprender prescripciones dogmáticas, mala distribución de las materias y graves omisiones.

${ }^{31}$ Deshayes, Florent, Memento juris ecclesiastici (París, 1897). Al igual que Pillet, el autor, canónigo de Mans, organiza las materias siguiendo la estructura de las Instituciones y redacta el articulado a la manera del Código napoleónico, lo que llevó a Ruffini a hablar de "códigos al estilo francés". Significativas fueron las elogiosas palabras dirigidas a Deshayes por el Papa León XIII en respuesta al obsequio de su Memento [su texto en Andrieu-Guitrancourt, Pierre, Introduction a l'étude du droit en general et du droit canonique contemporain (Paris, 1963), p. 878 n. 1]. Poco antes, el propio obispo del autor, le había felicitado, poniendo de relieve que "la exposición es nítida, consistente y precisa; el estilo es simple y muy claro. La edición es cómoda y todo se separa de manera de facilitar una búsqueda [...] El Memento será, por consecuencia, de mucha utilidad y los sacerdotes versados en la ciencia encontrarán en él, de una mirada, el encadenamiento y la deducción de series de cuestiones que, a la larga, se dispersan un poco en la memoria”. En pocas palabras, el prelado había resumido los beneficios de un código que ahora el canónigo francés presentaba como una realidad posible para la Iglesia.

${ }^{32}$ Pillet, Albert, cit. (n. 26). El autor organiza las materias siguiendo la estructura de las Instituciones, redactando el articulado a la manera del Code Civil, con la intención de mostrar que era posible elaborar un código que comprendiera todo el Derecho canónico vigente "in brevibus et lucidis formulis". Posteriormente sería consultor de los trabajos de codificación.

${ }^{33}$ Colomiatti, Emmanuel, Codex iuris pontifici seu canonici (Torino, 18881893), 9 vols. Aunque este autor divide su obra en 1742 cánones, este proyecto se asemeja más a las colecciones canónicas tradicionales, pues los cánones reciben constituciones pontificias y decretos conciliares sin ninguna modificación.

${ }^{34}$ Pezzani, Enricus Maria, Codex Sanctae catholicae romanae Ecclesiae, cum notis (Romae, Mediolani, 1893). Aunque quedó inacabado, tuvo resonancia en su época al ser superior que los de Deshayes y Pillet tanto en el estilo de redacción como en la división de las materias.

${ }^{35}$ Cadena y Eleta, José, Proyecto de Código procesal canónico (Madrid, 1895).

${ }^{36}$ PÉRIEs, George, La procedure canonique moderne dans les causes disciplinaires et criminelles. Notions pratiques sur les tribunaux ecclésiastiques et le fonctionnement des officielités (Paris, 1898). 
referidos a aspectos parciales, en concreto, la materia procesal.

La falta de estudios impide emitir un juicio acabado sobre el influjo concreto que estos intentos privados de codificación canónica pudieron haber tenido en la codificación oficial que se iniciaría poco después. Por de pronto, alguno de ellos como Pillet y Deshayes, participaron en los trabajos de preparación del futuro Código canónico por lo que, por esta vía, pudo sentirse alguna influencia. Parece, sin embargo, que puede afirmarse que quizá el efecto más importante, especialmente de los trabajos de Pillet, Deshayes y Pezzani, es que demostraron que era posible una codificación completa del Derecho canónico según la modalidad fijadora de los códigos estatales. El modo de redacción de los artículos y la sistemática empleada en los tres proyectos imitan claramente la técnica de los códigos estatales, si bien el contenido de los artículos se aleja a veces de lo propiamente jurídico, acogiendo cuestiones dogmáticas o morales. Esto último podría explicarse en la finalidad didáctica que los autores han dado a sus obras, además de la fuerte vinculación que siempre ha existido en Derecho canónico entre lo jurídico, lo moral y lo teológico.

Más importante aún es que "el análisis de la regulación concreta revela un rechazo absoluto de los principios ideológicos que subyacieron en los movimientos intelectuales artífices teóricos de las codificaciones civiles: del racionalismo filosófico y el liberalismo político de la Escuela de Derecho natural y de la Ilustración. Efectivamente. A pesar de adoptar la técnica codificadora, los proyectos privados reciben en su integridad la doctrina típica del Derecho público externo formulada por los tratadistas de la época" ${ }^{37}$. Pero eso sí, estos códigos privados favorecen, a través de su regulación, el afianzamiento del poder centralizado en la Iglesia.

A pesar de todas estas voces, durante el pontificado de León XIII nada oficial se hizo sobre el tema, aun cuando se ha señalado que León XIII y el cardenal Rampolla habían preparado un proyecto de codificación ${ }^{38}$. De esta misma época es esta otra información referida, esta vez, al obispo chileno Rafael Fernández Concha: "En enero de 1889 emprendió viaje a Roma. Llevaba consigo los manuscritos de su incomparable 'Teología mística', que en ese mismo ańo hizo imprimir en Barcelona. Cuando estuvo en Roma, habíale precedido la fama de sus libros, mereciendo las felicitaciones de todos. Su Santidad León XIII habló con él. Le sugirió que recopilara toda la legislación canónica vigente entonces. El prelado chileno le respondió que se consideraba demasiado viejo para llevar a cabo una obra semejante" 39 .

${ }^{37}$ Motilla, Agustín, cit. (n. 8), p. 701.

${ }^{38}$ Andrieu-Guitrancourt, Pierre, cit. (n. 31), p. 878, quien agrega que este dato hay que tomarlo con precaución.

${ }^{39}$ Ayala Godoy, Hugo, Rafael Fernández Concha (Memoria Universidad de 
Desconozco el origen de esta información que este autor no proporciona; quizá le fue ofrecida oralmente por alguno de los contemporáneos de Fernández Concha que él entrevistó. La información es muy genérica, si bien el modelo fijador que sugiere el Papa es el tradicional de la recopilación y no de la codificación. En todo caso, se trataría de un dato de no escasa importancia, toda vez que pone de relieve el interés del Pontífice por hacerse eco de las voces que por esos años están poniendo la voz de alerta sobre el caótico estado del Derecho de la Iglesia, una de cuyas dificultades era, precisamente, determinar cuál era el Derecho vigente. Fue, sin embargo, su sucesor, san Pío X, quien asumió la codificación del Derecho canónico.

\section{LA CODIFICACIÓN DEL DERECHO CANÓNICO}

\section{La idea de una revisión del Derecho canónico ${ }^{40}$.}

No es posible todavía precisar el nacimiento de la idea de revisar el Derecho canónico, pues han sido tres las opciones que hasta hoy tratan de explicarlo $^{41}$. Según una primera explicación, la idea habría surgido en el Papa la misma noche del día de su elección, el 4 de agosto de 1903, durante unas horas insomnes ${ }^{42}$. Corrobora esta hipótesis el que fuera su cardenal secretario de Estado ${ }^{43}$, quien escribió que "tres día después de su elevación

Chile, Santiago, 1947), p. 25.

${ }^{40}$ La literatura acerca de la historia de la codificación del Derecho canónico de 1917 no es escasa y toda ella se ha hecho con las escasas informaciones que estaban al alcance de los investigadores. Además de la citada in fine se puede mencionar la siguiente: AA. Vv. [con notas de la redacción de la Revista] Sunto del Codex Iuris Canonici e Il Codice di Diritto Canonico. Riasunto e dilucidazioni, en Il Monitore Ecclesiastico 30 (1918), pp. 18-27. Esta primera entrega se dedicó a las noticias históricas sobre la codificación en general, mientras en las entregas siguientes se hicieron comentarios a diversos libros del Código, en los que no están ausentes brevísimas referencias a la historia de la codificación: $50-62,85-90,115-122,149-158,182-$ 190, 213-222, 270-284, 306-316; 31 (1919), pp. 36-47, 80-88, 112-117, 145-155, 177-187, 347-363,; 32 (1920), pp. 17-26, 115-124, 185-194, 288-299, 337-340, 363-373; 33 (1921), pp. 15-27, 67-73, 113-119, 151-159, 181-188, 211-218, 272283, 340-351, 363-369; 34 (1922), pp. 16-21, 57-61, 87-91, 111-115, 146-149, 205-211, 270-274, 298-301, 335-339, 359-364.

${ }^{41}$ Llobell, Joaquín - De León, Enrique - Navarrete, Jesús, Il libro "De processibus" nella codificazione del 1917. Studi e documenti (Giuffré, Milano, 1999), I, pp. 25-27.

${ }^{42}$ Hilling, N., Die Reformen des Papstes Pius X. auf dem Gebiete der kirchenrechtlichen Gesetzgebung, en Archiv für katolisches Kirchenrecht 95 (1915), p. 41. La cita ibíd., p. 25 n. 18.

${ }^{43}$ Merry del VAl, Rafael cardenal, Pio X: impresioni e ricordi (Padova, 1949), p. 92 . 
al Pontificado, manifestó su firme intención de poner mano en tan grandioso trabajo [la codificación], que siempre había deseado ver coronado". Su intensa vida pastoral le habría llevado a experimentar personalmente la necesidad de tal empresa; "como párroco y obispo, había tenido ocasión de comprobar la imposibilidad de regir bien una parroquia o una diócesis con normas complejas esparcidas aquí y allí en antiguas compilaciones, dificilísimas de encontrar, las cuales, además de no ser tal vez congruentes consigo mismas, ya no se adaptaban a las nuevas condiciones de su tiempo" ${ }^{44}$. Hay quien, sin embargo, entiende que esta hipótesis no podría ser considera verdadera, pues el mismo Papa, y esta es la segunda explicación, el 11 de enero de 1904 escribe al cardenal Casimiro Gennari (1839-1914) ${ }^{45}$, agradeciendo la "santa sugerencia" y haciéndole presente que sería oportuno dar principio al trabajo "demasiado necesario" del estudio para dar inicio a compilación del "Código canónico" ${ }^{46}$. Finalmente, el cardenal Pedro Gasparri (1852-1934) ${ }^{47}$ ha escrito que después de su entronización, el Papa Pío X lo recibió en su calidad de secretario de la Congregación para los asuntos eclesiásticos extraordinarios y le preguntó acerca de las cosas que debían hacerse en dicho momento, a lo que el cardenal le habría respondido poniendo de relieve la necesidad de un Código canónico ${ }^{48}$.

Cual de estas tres explicaciones sea la exacta no es una cuestión que lleve aparejadas consecuencias importantes para la historia de la codificación. Incluso, como se ha puesto de relieve ${ }^{49}$, es posible que todas ellas sean

${ }^{44}$ Dal-Gal, Jerónimo, San Pío X (trad. castellana, 2a ed., Barcelona, 1954), p. 210.

${ }^{45}$ Sobre este cardenal se puede ver Palazzini, P., Gennari Casimiro, en Enciclopedia Cattolica (Città del Vaticano, 1951), VI, col. 8-9; Fagroli Vercellone, G. G., Gennari Casimiro, en Dizionario biografico degli italiani (Roma, 1999), LIII, pp. 114-116.

${ }^{46}$ Falco, Mario, Introduzione allo studio del Codex iuris canonici (1925, Bologna, 1992), p. 103. En dicha carta se puede leer: "Facendo tesoro del santo suggerimento, che l'Eminenza Vostra mi ha dato, conviene dar principio all'opera troppo necesaria dello Studio per la compilaciones del Codice Canonico; e percio prego l'Eminenza Vostra de preparare un brevísimo Motu Proprio da spedirsi a tutti quegli E. mi Cardinali e Consultori, che in seguito designeremo insieme, come i piu abili per tale lavore".

${ }^{47}$ Gasparri, Pedro, card., Storia della codificazione del diritto canonico per la Chiesa latina, en Pontificium Institutum Utriusque Iuris, Acta congressus iuridici internationalis. VII saeculo a Decretalibus Gregorii IX et XIV a Codice Justiniano promulgatis. Romae 12-17 novembris 1934 (Romae, 1937), IV, p. 4.

${ }^{48}$ Palazzini, P., Gasparri Pietro, en Enciclopedia Cattolica (Cità del Vaticano, 1950), V, col. 1954-1955; Astorri, R. - FantappiÉ, C., Gasparri Pietro, Dizionario biografico degli italiani (Roma, 1999), LII, pp. 500-507.

${ }^{49}$ Llobell, Joaquín - De León, Enrique - Navarrete, Jesús, cit. (n. 41), pp. 26-27. 
plausibles: el cardenal Gasparri puede haber dicho al Papa el comentario que se atribuye y el Papa haber considerado la oportunidad de codificar las leyes de la Iglesia, pero sin que tal pensamiento fuese seguido de una decisión operativa, la que se habría producido después de la sugerencia del cardenal Gennari.

Hay, sin embargo, algún elemento de juicio que permite dar mayor relieve a la primera de las hipótesis. En un artículo publicado en 1917 por uno de los consultores, el P. Noval ${ }^{50}$, cuenta como, con ocasión de la primera reunión plenario de los consultores, el Papa Pío X se habría dirigido a él "en estos términos poco más o menos: en los primeros días después de mi elección al Pontificado, pueden ustedes suponer que pasaba gran parte de la noche en vela. Entre los muchos pensamientos que con más insistencia me acosaban quitándome el sueño, era uno el de la dificultad que, dada la incertidumbre en muchas de las leyes, había yo de encontrar para resolver conforme a justicia y a Derecho tantos y tan graves asuntos como luego comenzaron a ser propuestos a mi decisión, ya para armonizar el celo con la prudencia al apremiar con la observancia o al querer reprimir la transgresión de muchas leyes fácilmente desconocidas. Parecióme que gran remedio sería hacer una codificación general: propuse el proyecto a personas doctas y prudentes, quienes lo juzgaron bueno y factible a pesar de sus dificultades innegables y en otros tiempos invencibles, y de aquí provino, después de implorar por varios meses los auxilios divinos, el decreto de codificación y el llamamiento de ustedes a trabajar en ella".

\section{El inicio de los trabajos.}

El primer documento conocido en torno a la codificación del Derecho canónico es la carta que el 11 de enero de 1904 dirigió el Papa san Pío X al cardenal Gennari ${ }^{51}$ en que le solicita la redacción de un "brevísimo" motu proprio para ser enviado a los cardenales y consultores que, después de su elaboración, fuesen considerados adecuados para desarrollar tal trabajo ${ }^{52}$. La respuesta del cardenal, una relación manuscrita de ocho páginas ${ }^{53}$, se

${ }^{50}$ Noval, José, El Código de Derecho Canónico compuesto por mandado del sumo pontifice Pio X promulgado por autoridad e S. S. Benedicto XV. Indicaciones históricoapologéticas sobre la codificación piano.benedictina, e idea general del Código y mudanzas más importantes, en La ciencia tomista 16 (1917), p. 147. La cita es de FANTAPIE, Carlo, Pio X e il Codex iuris canonisi, en Cattaneo, Arturo (a cura di), L'eredita giuridica di san Pio X (Marcianum Press, Venecia, 2006), pp. 158-159.

${ }^{51}$ Se publicó en Monitore Ecclesiasticus (1917), pp. 269 ss. bajo el título Il Codice canonico e il nostro fondatore.

${ }^{52}$ En esta parte sigo de cerca la detallada relación que proporcionan LlOBELL - De León - Navarrete, cit. (n. 41).

${ }^{53}$ ASV. CIC 17, scat. 1. 
produjo al mes siguiente y constituyó la base del motu proprio que daría inicio a los trabajos codificadores. Según Feliciani ${ }^{54}$, la proposición del cardenal se define claramente a favor de la redacción de un código en el que, a manera de lo que sucedía con el Derecho de los Estados, se expusiese de manera clara y ordenada toda la legislación canónica, opción que no tiene fundamentos ideológicos, sino que se basa sólo en motivos de técnica jurídica.

La carta al cardenal Gennari se imprimiós ${ }^{55}$ el mismo mes de febrero junto con una exposición de Pedro Gasparri ${ }^{56}$ en la que, partiendo del imperio romano, hacía una síntesis histórica de la legislación canónica, mostrando los diversos proyectos compilatorios, para terminar reafirmando la urgente necesidad de dar un nuevo ordenamiento y una nueva forma al Derecho canónico como respuesta al desorden existente. El texto estaba destinado a los cardenales de la Congregación de asuntos eclesiásticos extraordinarios de la que Gasparri era el secretario, quienes debían responder a las siguientes tres dudas que les proponía el Papa: i) si convenía dar al Derecho canónico un nuevo ordenamiento y una nueva forma. En caso de respuesta afirmativa; ii) cuál debía ser este nuevo ordenamiento y esta nueva forma. iii) si y con cuales modificaciones convenía publicar el motu proprio acompañado ${ }^{57}$.

La primera reunión de cardenales se celebró el 3 de marzo de $1904^{58}$ y en ella hubo una respuesta afirmativa unánime a la primera duda propuesta por el Papa. La respuesta a la segunda duda, en cambio, originó debate: no estaba claro si el trabajo a emprender era una consolidación del Derecho vigente o una nueva codificación; lo primero significaba conservar el contenido del Derecho vigente, pero liberado de los problemas formales $\mathrm{y}$ con las modificaciones de fondo que fueran necesarias, expuesto en una

\footnotetext{
${ }^{54}$ Feliciani, Giorgio, Lineamenti di ricerca sulle origine della codificación canonica vigente, en Annali di Macerata (1982), pp. 213-214.

55 (Con Segreto Pontificio). Sacra Congregazione degli Affari Ecclesiastici Straordinari, Codificazione del Diritto Canonico (Roma, Febraio, 1904), 31 pp. Las primeras 26 páginas correspondían al texto de Gasparri y las últimas 5 al del cardenal Gennari. Ibíd.

${ }^{56} \mathrm{El}$ texto manuscrito de 26 folios, ibíd.

57 "I. Se convenga dare al diritto canonico un nuovo ordinamento ed una nuova forma. E quatenus affirmative: II. Quale dovrebbe essere questo nuevo ordinamento e questa nuova forma. III. Se e con quali modificazioni convenga pubblicare il Motuproprio qui apresso".

${ }^{58}$ Participaron los cardenales Serafino Vannutelli, Agliardi, Vincenzo Vannutelli, Rampolla, Gotti, Ferrara, Caseta, Gennari, Cavicchioni, Steinhuber, Segna, Vives y Tutó, Cavagnis y Merry del Val, más el secretario Gasparri. Eran los mismos propuestos por el cardenal Gennari, a los que se agregaba Rafael Merry del Val.
} 
nueva colección. La segunda, significaba emprender la confección de un nuevo texto legal que derogase el Derecho anterior y se transformase en la nueva legislación de la Iglesia.

En cuanto a la tercera duda formulada por el Papa a los cardenales, estos se limitaron a hacer presente que se debía limitar al nombramiento de una comisión para el estudio y propuesta de las oportunas selecciones al respecto. Después de ser informado el Papa de esta primera reunión, dispuso una nueva reunión para que los cardenales volviesen a tratar el tema de la nueva colección discutido a propósito de la segunda de las dudas propuestas por el Papa en la primera reunión ${ }^{59}$.

En el impreso de seis páginas con que Pedro Gasparri convocó la nueva reunión, hace un resumen de lo tratado en la reunión anterior que resulta interesante en lo que se refiere a la segunda duda. Explicaba Gasparri que, en relación con esa duda, todos habían admitido: " $1^{\circ}$ que el actual Corpus iuris canonici debe ser mantenido en su valor jurídico, menos en aquellos puntos que habían sido o que deberían modificarse; $2^{\circ}$ que conviene hacer un código compendioso, de toda la legislación eclesiástica, distribuido con orden lógico y por artículo, a modo de los recientes códigos civiles, y que podría también llamarse manual, prontuario, breviario, formulario del Derecho canónico vigente ${ }^{60}$ ". Agregaba Gasparri que el Papa deseaba que los cardenales reconsideraran libremente la necesidad o la oportunidad de poner en obras esta nueva colección, teniendo presente las siguientes observaciones: i) se considera un punto cierto que las leyes precedentes conservarían su vigor a menos que fuesen modificadas por el Código, caso en el cual éstas tendrían valor prevalente; ii) los artículos del nuevo Código, en la medida de lo posible, mantendrían el mismo tenor literal de las leyes de que habían sido tomados, razón por la que la única ventaja de la Colección postulada por los cardenales sería reunir los documentos de los cuales se hubiese obtenido un cierto número de artículos; iii) si no se hiciera esta recopilación nada impediría pasar revista a los documentos más importantes a fines del Código; el resto de los documentos, o por lo menos la parte más interesante, sería citado por los autores que comentarían el Código promulgado en nota a pie de página en correspondencia con los respectivos artículos o cánones; iv) la necesidad del momento requiere normas precisas en la disciplina eclesiástica, en la enseñanza, en la administración de los sacramentos, en el gobierno de las diócesis, etc., a todo lo cual se hace frente de modo adecuado con el Código de manera

59 "[...] ut circa novam Collectionem ab ultima Collectione Corporis juris ad nostra usque tempora, rursus E.mi Patres audiantur".

60 “[...] manuale, promptuarium, breviarium, formularium iuris canonici vigentis". 
que la nueva colección, demasiado costosa, parece más o menos inútil, y sugiere a los cardenales proponer desde ese momento una nómina de consultores, italianos o extranjeros, a quienes invitar a colaborar en el Código canónico.

En la reunión sucesiva, los cardenales volvieron a afirmar que la fuente en que debía inspirarse tanto el Código como la nueva colección, sea que se hiciese sólo el primero o se redactaran ambos, no deberían perder su fuerza jurídica; además, opinaban que debía afrontarse simultáneamente las dos tareas porque los consultores, para hacer el Código debían tener ante sus ojos los documentos que quedaban así a mano para ser coleccionados. Las divergencias se produjeron sólo en cuanto a la oportunidad de publicar simultáneamente el Código y la nueva colección.

A la luz de estas primeras reuniones, que son el precedente inmediato del motu proprio pontificio que dispuso la revisión del Derecho canónico, se puede entender que tanto el Papa como los cardenales estaban de acuerdo: i) en que se hacía del todo necesario abordar la revisión del Derecho canónico; ii) que esa revisión debía significar una consolidación del Derecho vigente, el que debía mantener su vigencia; iii) la conservación de la vigencia del Derecho pasaba por conservar, incluso, el texto en el que estaba redactado; iv) que, no obstante conservarse sustancialmente el Derecho vigente, debían introducirse al mismo las reformas de fondo que lo adecuaran a la realidad actual de la Iglesia; v) no quedaba claro, sin embargo, si el nuevo Código del que se habla permanentemente debía adoptar la forma de un código como los que ya estaban vigentes en los Estados, siguiendo el modelo de la codificación iusracionalista, si bien parece que la idea subyacente al uso de la palabra era precisamente esa. Los hechos posteriores corroboran esta afirmación.

Para el Papa, sin embargo, el Código era el instrumento más idóneo para estabilizar el Derecho canónico, para restituir certeza a las normas, para garantizar la aplicación de la disciplina en los diversos ámbitos en los que se ejercía la actividad potestativa de la Iglesia. Esta idea aparece reforzada en las sucesivas observaciones pontificias que adoptaron dos de las esenciales características de la codificación: i) la simplificación del Derecho, consistente según Pío X, en extender en breves artículos las prescripciones del Derecho, sin agregar, según el viejo método de los comentaristas, demostraciones ni alegaciones; ii) la actualización del Derecho que el Papa entendía como abandonar todo lo que estaba derogado, reformando y agregando lo que faltaba en la legislación eclesial; desde esta perspectiva, el trabajo codificador no era, entonces, un simple reflejo del Derecho vigente vertido a una forma novedosa de exposición, sino una operación de ius condendum, un proceso, al mismo tiempo, de selección 
y de renovación de las normas ${ }^{61}$.

Adoptar la forma de código para el Derecho de la Iglesia significaba, sin embargo, un cambio demasiado brusco respecto de la forma en que, a lo largo de los siglos, se había desenvuelto el ius vetus, incidiendo a fondo en la el a s t i ci d a d que había sido la indiscutida y fértil peculiaridad del Derecho de la Iglesia ${ }^{62}$. La técnica codificadora no sólo era extraña a la cultura católica, sino que simbolizaba una de las señales típicas y de los elementos de fuerza de los Estados contrapuestos a la Iglesia. Había, con todo, razones que aconsejaban acoger esta moderna modalidad fijadora del Derecho aparte de los innegables beneficios formales de la misma: si la Iglesia se entendía a sí misma como una societas iuridice perfecta como lo eran los Estados, sustituir el Corpus por un Codex, esto es, por la modalidad que los Estados habían escogido para presentar su Derecho, era una demostración coram omnibus del logrado reconocimiento de esa perfección. Por otra parte, en una Iglesia que veía amenazada su libertad con la invasión de los Estados Pontificios y que se sentía asediada, el Codex, con la generalidad y rigidez que le caracterizaban, era el instrumento adecuado para el control y centralización de una juridicidad canónica que resultaba poco controlable al estar entregada, la más de las veces, a doctores inmersos en escuelas y corrientes doctrinales, y a jueces dispersos en el atomismo de las mil y una contiendas particulares. En todo caso, era claro que el Código no era un fin en sí mismo sino un instrumento para ayudar a los fieles a la conquista de su salvación eterna ${ }^{63}$.

\section{El "motu proprio Arduum sane munus" y las comisiones de trabajo.}

El 19 de marzo de 1904, dos días después de la segunda de las reuniones cardenalicias, se promulgó el m. p. Arduum sane munus ${ }^{64}$, con el que el

${ }^{61}$ Fantapie, Carlo, Pio X e il Codex iuris canonisi, en Cattaneo, Arturo (a cura di), L'eredita giuridica di san Pio X (Marcianum Press, Venecia, 2006), pp. 160.

${ }^{62}$ El nombre de "código" había sido raramente usado en las colecciones canónicas y ello en tiempos bastante antiguos: Codex Ecclesiae Hispaniae (s. VII), Codex canonum (s. VIII), Codex canonum Ecclesiae Africanae (s. V); por lo demás, el nombre de "código" para estos dos últimos se los había dado sólo el uso.

${ }^{63}$ Grossi, Paolo, Valore e limiti della codificazione del diritto (con qualche annotazioni sulla scelta codicistica del legislatore canonico, en CATtaneo, Arturo (a cura di), L'ereditá giurdica di san Pio X (Venecia, Marcianum Pres, 2006), pp. 142-143.

${ }^{64}$ ASS. 36 (1903-1904), pp. 549-551. El m.p. lleva la fecha 14 de abril de 1904, pero parece que se trata de un error de imprenta, pues en la carta circular Pergratum mihi, fechada el 25 de marzo de 1904, hay una referencia expresa al m.p. Arduum sane munus. Son de esta opinión, Llobell, Joaquín - De León, Enrique - Navarrete, Jesús, cit. (n. 41), p. 34 n. 30 . Al parecer, en la redacción de este m.p. influyó el postulado que 33 obispos de diversas naciones habían hecho en el concilio Vaticano I, en el que se lee "Opus sane arduum, sed quo plus difficultatis habet, eo magis est tanto Pontifice dignum". 
Papa Pío X daba inicio oficial a la codificación del Derecho canónico. Se le conoce con este nombre, siguiendo la práctica de identificar los documentos pontificios con las primeras palabras de su texto; pero fue publicado bajo un título decidor: De Ecclesiae legibus in unum redigendis, esto es, acerca de la unificación de las leyes de la Iglesia. El texto de la misma se iniciaba recordando el Papa la meta que él se había impuesto con su pontificado de restaurar todo en Cristo ${ }^{65}$, siendo sobre todo la disciplina eclesiástica la que debía contribuir a cumplir ese alto cometido. Era por lo que, acogiendo las distintas voces que pedían una revisión del Derecho canónico, había tomado la decisión de preparar su cumplimiento para lo cual tomaba las decisiones siguientes: $1^{\circ}$ la constitución de una comisión pontificia que tendría a su cargo la dirección de esta tarea, que estaría compuesta por un determinado número de cardenales que serían designados nominativamente por el Papa ${ }^{66} ; 2^{\circ}$ este consejo sería presidido por el Papa y, en su ausencia, por el decano de los cardenales presentes ${ }^{67} ; 3^{\circ}$ habría, además, un número conveniente de consultores que serían escogidos por los cardenales, con la aprobación del Papa, de entre los más instruidos en Derecho canónico y en teología ${ }^{68} ; 4^{\circ}$ el Papa manifestaba su deseo que todo el episcopado, conformándose a las reglas que serían dadas en tiempo oportuno, colaboraran y concurrieran a esta obra tan importante $e^{69} ; 5^{\circ}$ Una vez que estuviera fijado el método a seguir en este estudio, los consultores prepararían los textos y emitirían sus pareceres en reuniones presididas por quien el Papa nombrara secretario de la comisión cardenalicia. Los estudios y pareceres de los consultores serían en seguida objeto de una madura deliberación por parte de los cardenales. Todo, finalmente, sería sometido al Soberano Pontífice para su legítima aprobación ${ }^{70}$.

${ }^{65} \mathrm{La}$ expuso en su primera encíclica Instaurare omnia in Christo, en Pii X Acta 1, pp. 1-16.

66 "I. Consilium, sive, ut aiunt, Commissionem Pontificiam constituimos, quam penes erit totius negotii moderatio et cura, eaque constabit ex nonnullis $S$. R. E. Cardinalibus, a Pontifice nominatium designandis".

67 "II. Huic Consilio ipse Pontifex praeerit, et Pontifice absente, Cardinalis decanus inter adstantes".

68 "III. Erunt praeterea iusto numero Consultores, quos Patres Cardinales e viris canonici iuris ac theologiae peritissimis eligent, Pontifice probante".

${ }_{69}$ "IV. Volumus autem universum episcopatum, iuxta normas opportune tradendas, in gravissimum hoc opus conspirare atque concurrere".

70 " $V$. Ubi fuerit constituta ratio in huiusmodi studio sectanda, Consultores materiam parabunt suamque de ipsa sententiam in conventibus edent, praeside illo, cui Pontifex mandaverit Concilii Cardinalium esse ab actis. In eorum deinde studia et sententias PP. Cardinales matura deliberatione inquirent. Omnia denique ad Pontificem deferantur, legitima approbatione munienda". 
El motu proprio evitó pronunciarse por alguna de las dos opciones que se barajaban para la renovación de las leyes de la Iglesia: la colección o la codificación; más aún, la generalidad de la terminología utilizada permitía una u otra opción.

a) La comisión pontificia de cardenales. Los nombres de los 16 cardenales que debían integrar la comisión pontificia se publicaron inmediatamente, a continuación del motu proprio ${ }^{71}$; ellos eran: Serafino Vannutelli (1834-1915), Antonio Agliardi (1832-1915), Vincenzo Vannutelli (1836-1930), Francisco Satolli (1839-1910), Mariano Rampolla del Tíndaro (1843-1913), Jerónimo M. Gotti (1834-1916), Domingo Ferrata (1847-1914), Francisco de Paula Caseta (1841-1919), Francisco Desiderio Mathieu (1839-1908), Casimiro Gennari (1839-1914), Benjamín Cavicchioni (1836-1911), Rafael Merry del Val (1865-1930), Andrea Steinhuber (1824-1907), Francisco Segna (1836-1911), José de Calasanz Vives y Tutó (1854-1913), y Felices Cavagnis (1841-1906). Allí mismo, a continuación de los nombres de los cardenales, se nombró secretario de la comisión pontificia a Pedro Gasparri, antiguo profesor en el Instituto católico de Paris, entonces arzobispo titular de Cesarea y secretario de la Congregación de asuntos eclesiásticos extraordinarios, a quien se le nombró al mismo tiempo presidente de la Comisión de consultores. De todos los cardenales nombrados, tan sólo tres verían la obra finalizada (Vincenzo Vannutelli, Cassetta y Merry del Val), pues los demás fallecieron antes del término de la misma, algunos en fecha tan temprana como 1906 (Cavagnis) y 1907 (Steinhuber). Es por lo que nuevos cardenales fueron incorporándose a los trabajos codificadores: S. Martinelli, Gaetano de Lay, B. Pompili, G. van Rossum, G. Bisleti, F. Giustini y M. Lega.

La competencia de esta comisión pontificia de cardenales era la siguiente: i) proponer la nómina de los primeros consultores; ii) aprobación definitiva del índice de materias que debía contener el Código; iii) aprobación de los puntos más importantes, especialmente de aquellos que comportaren modificaciones o agregados al Derecho vigente; iv) aprobación del proyecto definitivo del Código antes de ser presentado al Papa.

Poco después Gasparri dispuso que un grupo reducido de cardenales examinase los puntos que no presentaban dificultades particulares o no innovasen en la disciplina vigente. Su principal función fue examinar el trabajo desarrollado precedentemente por los consultores.

b) El reglamento. El 11 de abril se aprobó el Regolamento per la Commissione Pontificia istituita dal Santo Padre per la Codificazione del Diritto

${ }^{71}$ ASS. 36 (1903-1904), p. 551. 
Canonico $^{72}$, elaborado, al parecer, por el secretario de la Comisión, Pedro Gasparri $^{73}$, texto del que cabe poner de relieve los siguientes aspectos: i) la codificación debería abrazar la sola parte disciplinar de la legislación eclesiástica, lo que no impediría que en el Código pudiesen o debiesen figurar algunos principios pertenecientes al Derecho natural o al dogma (artículo 6); ii) las materias que deberían formar parte del Codex y su subdivisión serían objeto de un estudio preliminar por parte de los consultores y del congreso plenario de cardenales, lo que debía hacerse de inmediato (artículo 7); iii) en la compilación de los cánones o artículos los consultores debían conservar, en la medida de lo posible, las palabras de los documentos de las que eran extraídas, las que debía ir entre comillas ("'), cuidando al mismo tiempo la brevedad y la claridad, indicando en cada caso la página, el volumen y la edición del documento del cual eran extraídos (artículo 8); iv) uno o más consultores nombrados por el secretario tendrían el encargo de anotar los documentos de los cuales eran extraídos dichos cánones o artículos, con excepción de los que provenían del Corpus Iuris Canonici o del Concilio de Trento (artículo 9) ${ }^{74}$.

La idea de Gasparri, que es la que terminó por imponerse, era la formación de un código para la Iglesia que, siendo de contenido canónico, fuese elaborado al estilo de los modernos códigos estatales. Idea que reitera en la carta que dirigirá a los rectores de las universidades católicas a la que me refiero más adelante.

c) La comisión de consultores. La primera tarea de la comisión pontificia fue elegir los consultores que deberían llevar adelante la codificación. La nómina de los mismos fue comunicada por el Secretario de Estado, Rafael Merry del Val, a los obispos del mundo, por carta circular Pergratum mibi, de 25 de marzo de $1904^{75}$, a la que, en nota a pie de página, se agregaban otros

\footnotetext{
${ }^{72}$ Su texto ibíd., pp. 287-289.

${ }^{73}$ Llobell, Joaquín - De León, Enrique - Navarrete, Jesús, cit. (n. 41), pp. 40 41.

${ }^{74}$ Según el artículo 3 del reglamento, "la cooperación a esta obra grandiosa es gratuita".

${ }^{75}$ ASS. 36 (1903-1904), pp. 603-604. Se incluían en ella los siguientes 17 consultores: Albert Pillet, francés, prelado residente en la Curia romana; Alexius Lepicier, francés, entonces prior general de la Orden de los Siervos de María; Aloisius Veccia, italiano, secretario de la S. Congregación de Propaganda Fide; Alfonso Eschbach, francés, procurador general de la Congregación del Espíritu Santo y del Inmaculado Corazón de María; Bernardino Klumper, alemán, religioso de la Orden de los frailes menores; Cayetano de Lai, italiano, entonces secretario de la S. Congregación del Concilio; Carlos Lombardi, italiano, profesor de Derecho canónico en el Ateneo Seminario romano; Francisco Javier Wernz, jesuita alemán, profesor de Derecho canónico en la Universidad Gregoriana y posteriormente prepósito general de la
} 
veinticinco consultores ${ }^{76}$. Esta nómina inicial fue completada en los años siguientes con la incorporación de nuevos consultores y colaboradores ${ }^{77}$.

Compañía de Jesús; Guillermo Sebastianelli, italiano, auditor de la Rota Romana y profesor de Derecho canónico en el Seminario romano; Guillermo Van Rossum, alemán, religioso de la congregación del Santísimo Redentor; Laurentius Janssens, belga, religioso benedictino; Maurus Kaiser, oriundo de Luxemburgo, fraile dominico; Pedro Armengol Valenzuela, chileno, maestro general de la Orden de la Merced; Filipo Giustini, italiano, entonces secretario de la S. Congregación de obispos y religiosos; Pio de Langogne, francés, religioso de la Orden capuchina; Tomás Esser, alemán, fraile dominico y secretario de la S. Congregación del índice; Vicente Fernández y Villa, español, religioso de la Orden de san Agustín.

${ }^{76} \mathrm{Se}$ encontraban los siguientes prelados de curia: Ioannes Befani, italiano, auditor de la Rota Romana; Hermetes Binzecher, italiano; Aloisius Budini, italiano, subsecretario de la $\mathrm{S}$. Congregación de obispos y religiosos; Petrus Checchi, italiano, secretario del vicariato de la Urbe; Ioannes Costa, italiano; Ioannes de Montel, austriaco, auditor de la Rota Romana; Orestes Giorgi, italiano, entonces auditor de la S. Congregación de obispos y religiosos, posteriormente cardenal; Joseph Latini, italiano, promotor fiscal de S. O. y profesor de Derecho criminal en el Seminario romano; Michael Lega, italiano, entonces secretario de la S. Congregación del concilio; Evaristus Lucidi, italiano; Ioannes B. Lugari, italiano, entonces asesor S. O. y posteriormente cardenal; Dominicus Mannaioli, italiano; Benedictus Melata, italiano; Joseph Nervegna, italiano, sustituto de la S. Congregación para la disciplina de los regulares; Henricus M. Pezzani, italiano; Basilius Pompili, italiano; Augustus Sili, italiano. A los anteriores, se agregaban los siguientes religiosos: Claudius Benedetti, italiano, de la Congregación del Santísimo Redentor; Ianuarius Bucceroni, italiano, de la Compañía de Jesús, profesor de teología moral en la Universidad Gregoriana; Marianus De Luca, italiano, de la misma Compañía de Jesús, profesor de Derecho canónico en la Universidad Gregoriana; Albertus Lepidi, italiano, de la Orden de los Predicadores; Joseph Noval, espańol, también de la Orden de los Predicadores, profesor de Derecho canónico en el Colegio Santo Tomás; Benedictus Oietti, italiano, jesuita, profesor de Derecho canónico en la Universidad Gregoriana; Dominicus Palmieri, italiano, de la Compañía de Jesús, teólogo de la Penitenciaría Apostólica. Finalmente, D. Comes Baltasar Capogrossi-Guarna, italiano como la mayoría de los anteriores.

${ }^{77}$ Francisco do Rego Maia, brasileño, arzobispo titular Nicopolitano; Dominico Taccone Galluci, italiano, arzobispo titular Constantiensi; Seraphino Many, francés, religioso sulpiciano, auditor de la Rota Romana; Angelo Mariano, italiano, promotor de la fe; Nicolao Marini, italiano, secretario del Supremo Tribunal de la Signatura Apostólica, posteriormente cardenal; Maximo Massimi, italiano, auditor de la Rota Romana, profesor de Derecho romano en el Seminario romano; Francisco Parrillo, italiano, defensor del vínculo en la Rota Romana; Jeremia Rossi, italiano; Aloisio Sincero, italiano, auditor de la Rota Romana; Jacobo Sole, italiano, profesor de Derecho canónico en el Seminario romano; Francisco Spolverini, italiano, subdatario; Alexandro Verde, italiano, secretario S. R. C.; Pedro Bastien, benedictino belga, Camilo Beccari, italiano, de la Compañía de Jesús; Januario Bucceroni; Eustasio Esteban, español, religiosos de la Orden de San Agustín; Joaquín de san 
En esta larga nómina de consultores América Latina no estuvo ausente, si bien los consultores nombrados sólo fueron dos: el arzobispo titular de Nicopolis, de nacionalidad brasileña, don Francisco do Rego Maia; y el religioso mercedario chileno Pedro Armengol Valenzuela Poblete que por esos años se desempeñaba en Roma como ministro general de su orden.

Los consultores trabajaron de diversas maneras, la primera de las cuales fue la de reunirse en comisión plenaria de consultores. La primera reunión de la totalidad de los consultores nominados inicialmente, y probablemente la única en la que participaron todos ellos ${ }^{78}$, fue el domingo 17 de abril. Al inicio de la misma se tomó a todos los consultores el juramento de secreto servando según la fórmula de la $\mathrm{S}$. Congregación de asuntos eclesiásticos extraordinarios, y se distribuyó el Reglamento para la Comisión Pontificia instituida por el S. Padre para la codificación del Derecho canónico. Después el presidente les explicó la finalidad y la naturaleza del trabajo que debían realizar los consultores, puso de relieve tanto la dificultad de la empresa como su necesidad, reclamada tanto por los académicos como por el episcopado, y les dio a conocer el contenido de la carta dirigida al episcopado latino y a las universidades católicas. Acto seguido les planteo el primer tema que debían abordar cual era el de la división de las materias del futuro Código ${ }^{79}$.

Resuelto el primero de los temas, la comisión plenaria de consultores tenía la tarea de examinar los cánones aprobados por las comisiones menores -subcomisiones o comisiones especiales- antes de someterlos al estudio de la comisión pontificia de cardenales. El trabajo de la misma tuvo, sin embargo, inconvenientes, por el número elevado de personas que intervenían, por lo que dejó de reunirse, si bien el trabajo de los consultores continuó, pero ahora con una nueva modalidad: en lugar de las reuniones se enviaba a cada consultor los proyectos ya formulados e impresos para que, en el plazo de quince días, los devolviese con sus observaciones anotadas al margen de los cánones.

Como lo contó el mismo Gasparri ${ }^{80}$, si el trabajo era asumido por

Simón Stock, español, carmelita descalzo; José Laurentius, alemán, de la Compañía de Jesús; Alexio M. Lepicier; Rafael Molitor, benedictino alemán; Justiniano Seredi, benedictino húngaro; Miguel Sleutjes, religioso; Pedro Vidal, jesuita español, profesor de Derecho canónico en la Universidad Gregoriana; Felipe Maroto, español, procurador general de la congregación de los Misioneros hijos del Corazón de María, profesor de Derecho canónico en el Seminario romano; Felipe Pacelli, abogado; Augustino Rolli; Carlos Santucci, italianos.

${ }^{78}$ Llobell, Joaquín - De León, Enrique - Navarrete, Jesús, cit. (n. 41), p. 41.

${ }^{79}$ Ibíd.

${ }^{80}$ GaSParri, Pedro, Storia della codificazione del diritto canonico per la Chiesa lati$n a$, en Pontificium Institutum Utriusque Iuris, Acta congressus iuridici interna- 
una sola comisión que se reunía una vez a la semana, el Código no podría estar terminado antes de 25 años, por lo que él mismo insinuó al Papa la posibilidad de dos comisiones menores. Parece, sin embargo, que hubo más de dos comisiones especiales de consultores, integradas por pocos consultores y encargadas de materias bien determinadas. Pero parece que, dado el desarrollo de los trabajos, no funcionaron simultáneamente más de dos de estas comisiones en forma paralela ${ }^{81}$.

A los antedichos consultores, que residían en Roma y, por lo mismo, asistían a las consultas o reuniones de las comisiones, se agregarían también los c o la b o r a d o r es, esto es, canonistas o teólogos, romanos o extranjeros, a quienes se encargaba el estudio de alguna parte concreta en la redacción del nuevo Código. Esta distinción quedó recogida en el Anuario Pontificio en la que se diferencian ambas figuras ${ }^{82}$.

Desde el primer momento reinó el más completo silencio sobre el trabajo de las comisiones. Con el fin de evitar discusiones ociosas la Santa Sede decidió no proporcionar información alguna.

\section{La primera consulta al episcopado y a las universidades católicas.}

"Una de las principales características del proceso de codificación de 1917 consiste en la participación, promovida por la Santa Sede, del episcopado mundial en la elaboración del Código [...] la primera por lo que se refiere a un cuerpo legislativo" ${ }^{83}$. Dicha consulta estaba prevista en el artículo $4 \mathrm{del} \mathrm{m}$. p. Arduum sane munus y fue llevada a la práctica mediante la circular Pergratum mihi, de la Secretaría de Estado, de fecha 25 de marzo de 1904, enviada a todos los metropolitanos de la Iglesia ${ }^{84}$. En ella se disponía que los arzobispos, después de haber oído a sus sufragáneos y otros ordinarios que debían estar presente en el sínodo provincial, debían hacer llegar a la Santa Sede, dentro de los cuatro meses siguientes, en pocas palabras, las principales modificaciones y correcciones que debían hacerse al Derecho canónico en vigor. Como se indicaba en la misma circular, era deseo formal del Papa ver a todo el episcopado concurrir y tomar parte activa en un asunto que interesaba en grado máximo el bien y utilidad de toda la Iglesia católica ${ }^{85}$.

tionalis. VII saeculo a Decretalibus Gregorii IX et XIV a Codice Iustiniano promulgatis (Romae, 1937), IV, p. 6.

${ }^{81}$ Llobell, Joaquín - De León, Enrique - Navarrete, Jesús, cit. (n. 41), p. 64.

${ }^{82}$ Cf. Anuario Pontificio 1909, p. 447; 1913, p. 551; 1916, p. 571.

${ }^{83}$ Llobell, Joaquín - De León, Enrique - Navarrete, Jesús, cit. (n. 41), p. 46.

${ }^{84}$ ASS. 36 (1903-1904), pp. 603-604.

${ }^{85}$ Se solicitó la colaboración del episcopado para que los consultores, con frecuencia hombres más bien teóricos, fuesen iluminados por las condiciones de vida 
En la misma circular se comunicaba a los obispos que, por decisión del Santo Padre, los obispos de cada nación tenían la facultad de escoger y enviar a Roma, a su costo, uno o dos especialistas en Derecho canónico o teología, que pudiesen formar parte del grupo de consultores; si preferían escoger uno de los que ya habían sido nombrados consultores por los cardenales, podían encargarles que los representara para someter a discusión y defender sus proposiciones en las reuniones de los consultores; incluso, podían nombrar a alguno de su nación que, residiendo fuera de Roma, pudiese, por correspondencia, aportar de alguna manera a los consultores el apoyo de su colaboración.

La respuesta de los obispos del mundo fue amplia, contándose entre ellas la de numerosos obispos latinoamericanos, incluidos los chilenos. A diferencia de lo que había sucedido con la elaboración de las Decretales, que Gregorio IX había encargado a un solo compilador, san Raimundo de Peñafort, el Código fue obra de muchos: san Pío X quiso asociar en esta empresa al episcopado del mundo entero y también a las universidades católicas. Así, el Código fue a la vez expresión de la tradición, en la que Pío $\mathrm{X}$ quiso que se inspirasen fielmente, $\mathrm{y}$ resultado del esfuerzo asumido en común entre hombres de estudio y hombres de experiencia. Se calcula en aproximadamente cinco mil el número de personas que fueron consultadas por lo que, no sin razón, se ha dicho que el trabajo de consulta a los obispos fue como un concilio ecuménico por correspondencia.

El numeroso material reunido fue sistematizado según la estructura que se había definido en el índice de materias definido por los cardenales mientras se hacía la consulta, y reproducido en un volumen que permaneció inédito, bajo la dirección del consultor Bernardino Klumper, con el título Postulata Episcoporum in ordine digesta ${ }^{86}$. Posteriormente se agregó un segundo volumen, más breve que el anterior, con sólo 68 páginas, impreso en 1908 con el título Appendix ad Postulata Episcoporum, reproducido igualmente por Bernardino Klumper ${ }^{87}$ en el que se recogen, probablemente, las respuestas llegadas con retraso, cuando el primero de estos volúmenes ya estaba en prensa. Ninguno de los dos volúmenes llegó a empastarse y su circulación

particular en los diferentes países; la consulta era necesaria para asegurar que el nuevo Código tuviese un carácter eminentemente práctico y para que, gracias a las sugerencias de los obispos, se eliminasen todas las imperfecciones del Derecho vigente, introduciéndole al mismo tiempo las reformas necesarias. Vetulani, A., Codex Juris Canonici, en Dictionnaire de Droit Canonique (Paris, 1942), III, col. 920.

${ }^{86}$ Codex Iuris Canonicil Postulata Episcoporum/ in ordinem digestal al Rmo. P. Bernardino Klumper O. F. M./ Consultorel Romael Typis Vaticanis/ 1905/ 283 pp. ASV. CIC 17, scat. 4.

${ }^{87}$ ASV. CIC 17, scat. 6. 
quedó estrictamente restringida a los consultores, de manera que no fueron conocidos fuera de ellos. Preciso es tener presente, sin embargo, que no todos los postulata fueron recogidos por Klumper, si bien la mayoría lo fue; pero de estos, el consultor fue recogiendo lo que consideraba de utilidad o cambió de colocación las sugerencias iniciales, por lo que la consulta a los documentos originales se hace indispensable para poder conocer con precisión lo sugerido por los obispos ${ }^{88}$.

Como ha sido puesto de relieve ${ }^{89}$, estos postulata reflejan el sentir del episcopado mundial en lo que se refiere a la codificación y permiten conocer cuales eran las preocupaciones y los problemas que interesaban al episcopado mundial a los inicios del siglo XX, no sólo de orden jurídico, sino también eclesiológico, disciplinar, pastoral, etc.; desde esta perspectiva, los postulata constituyen una útil manera de aproximarse a las realidades de las iglesias locales de la época a partir de unos protagonistas tan directos como son los obispos de cada una de ellas. En ellos se solicitan soluciones que, en no pocos casos, sólo fueron adoptadas por el Concilio Vaticano II y el Código de Derecho Canónico de 1983.

Otra circular, esta vez de 6 de abril de 1904, atribuible al secretario de la Comisión Pedro Gasparri, fue dirigida a los rectores de las universidades católicas para pedirles el concurso "en esta empresa importante y difícil" metódicamente todo el Derecho canónico en cánones o artículos, a la manera de los códigos modernos y, al mismo tiempo, de hacer una recopilación de todos los documentos aparecidos después de las colecciones auténticas del Corpus Iuris de los que dichos cánones o artículos deberán ser tomados". Después de enunciar de manera resumida la distribución de las materias en el Código, les pedía que preguntasen a sus profesores de Derecho canónico qué partes del Derecho canónico estarían dispuestos a redactar en cánones o artículos; una vez recibidas las respuestas se les harían llegar instrucciones particulares en las que se darían a sus profesores todas las indicaciones prácticas. Análoga invitación recibieron también algunos profesores de Derecho canónico de universidades estatales.

Además de diversos votos y proyectos para las diversas materias del

${ }^{88} \mathrm{Al}$ no estar todavía generalizado el uso de la máquina de escribir, la mayoría de los postulata son manuscritos, lo que dificulta su lectura, a lo que hay que agregar el que ellos están escritos en diversas lenguas, porque no todos los obispos usaron el latín para sus respuestas, si bien un número importante usó la lengua oficial de la Iglesia.

${ }^{89}$ Llobell, Joaquín - De León, Enrique - Navarrete, Jesús, cit. (n. 41), pp. 47-48.

${ }^{90}$ Circular Perlegisti, en ASS. 37 (1904-1905), pp. 130-131. 
Código incluidos en las respuestas de las universidades, de los académicos mencionados, algunos fueron nombrados posteriormente consultores o colaboradores. Esta consulta a las universidades católicas mostró la utilidad de incorporar al trabajo codificador a canonistas bien preparados que trabajaban fuera de Roma quienes, además de aportar con su propia competencia, podían contribuir a enriquecer la legislación universal con las experiencias maduras de los Derechos particulares.

Con todo, y sin perjuicio de la riqueza que para los trabajos codificadores supuso el aporte del episcopado mundial y de las universidades católicas, "el hecho de que la comisión cardenalicia nombrada por el Papa, y todos los consultores, sean residentes en Roma, así como el completo secreto que rodea los trabajos de codificación y que impide cualquier participación fuera de las fronteras romanas, indica que la codificación se realizó según plan trazado por la Santa Sede cuyo fin era conseguir, sin polémicas ni interferencias, una mayor centralización de los poderes de la Iglesia. En el proceso codificador, aunque existan consultas al episcopado universal, la Santa Sede se reserva el Derecho de decisión y ejecución”"1.

\section{El indice de materias.}

Mientras se hacía la consulta al episcopado mundial y en espera de las sugerencias de los obispos, en Roma se trabajaba en definir la estructura del Index materiarum, esto es, el esquema que definía las materias que debía incluir el Código que se proyectaba ${ }^{92}$. En la circular Perlegisti enviada a las universidades católicas se incluía, de manera resumida, una primera enunciación de los contenidos del Código que se empezaba a preparar. El Código debía estar dividido en cinco libros que se abrían con una parte general, que debía comprender cuatro títulos: i) de Summa Trinitate et fide catholica, ii) de constitutionibus, iii) de consuetudine, y iv) de rescriptis. De los cinco libros siguientes se daba sólo el título: Liber I, De personis; Liber II, De sacramentis; Liber III, De rebus et locis sacris; Liber IV, De delictis et poenis; y Liber V, De iudiciis. Este esquema permite apreciar con claridad la intención de aproximarse al plan de las Instituciones canónicas cuyo uso se había popularizado en las exposiciones doctrinales del Derecho de la Iglesia después de que Paolo Lancelotti (+1590) publicara sus Institutiones Iuris Canonici ${ }^{93}$, inspirándose

${ }^{91}$ Motilla, Agustín, cit. (n. 8), p. 711.

${ }^{92}$ Los documentos referidos a la subdivisión de materias que debía incluir el Código pueden consultarse en Llobell, Joaquín - De León, Enrique - Navarrete, Jesús, cit.(n. 41), pp. 291-351.

${ }^{93}$ Lancelotti, Paolo, Institutiones iuris canonici (Perugia, 1563). Se puede ver Merello Arecco, Italo, Recepción de la sistemática Gayano-Justinianea por parte del Código de Derecho Canónico de 1917, en Revista de Estudios Histórico-Jurídicos 16 
en las Instituciones de Justiniano ${ }^{94}$.

Esta división, que fue conocida en su momento por los consultores, fue criticada. Después de algunas modificaciones y de otros tres proyectos impresos de división de las materias, el cuarto y último proyecto fue presentado a la audiencia de cardenales del 26 de junio de 1904 en la que, bajo la presidencia del Papa, fue aprobado definitivamente el Index materiarum Codicis Iuris Canonicip ${ }^{95}$. Se cumplía así lo dispuesto por el artículo 7 del reglamento.

La estructura general del índice dividía las materias en libros, partes, secciones, títulos y capítulos, sin que para todas las materias se utilizaran siempre todas estas subdivisiones. El índice se iniciaba con la fórmula de profesión de fe y se dividía en cinco libros según el siguiente detalle: el libro primero, dedicado a la parte general, estaba dividido en cinco títulos. El libro segundo, referido a las personas se dividía en tres partes dedicadas cada una, respectivamente, a los clérigos, los religiosos y los laicos. El libro tercero se dedicaba a las cosas, dividiéndose en seis partes referidas a los sacramentos, los lugares y tiempos sagrados, el culto divino, el magisterio eclesiástico, los beneficios eclesiásticos y los bienes temporales. El libro cuarto, referido a los delitos y las penas, estaba dividido en tres partes, a saber, los delitos en general, las penas, y los delitos en particular y sus penas. El libro quinto y final se refería a los juicios y estaba dividido en tres partes: los juicios en general, los juicios no criminales, y los juicios criminales. En suma se asumió en forma oficial que la estructura de los contenidos del Código quedaba dada por la ordenación de las instituciones.

Los cardenales habían sido llamados también a expresarse respecto

(1994), pp. 79-86.

${ }^{94}$ Hacia principios del siglo XVI el Derecho romano estaba contenido en el Corpus Iuris Civilis, en tanto que el Derecho de la Iglesia lo estaba en el Corpus Iuris Canonici. Al comparar uno y otro, se equiparó el Decreto de Graciano al Digesto, las Decretales de Gregorio IX al Código de Justiniano, el Liber Sextus, las Clementinas, las Extravagantes comunes y las Extravagantes de Juan XXII a las Novelas, pero faltaba el equivalente a las Instituciones justinianeas. Esa tarea la emprendió Paolo Lancelotti quien redactó sus Institutiones Iuris Canonici con la intención de que fueran incorporadas a las ediciones oficiales del Corpus Iuris Canonici, en lo que no tuvo éxito. Pero tuvo un éxito inesperado en el género literario que utilizó porque a partir de él fueron numerosos los autores que hicieron sus exposiciones del Derecho canónico con el género de las Instituciones. Incluso entre nosotros, en un período tan tardío como mediados del siglo XIX, Justo Donoso escogió el género de las instituciones para hacer sus difundidas Instituciones de Derecho canónico Americano (Valparaíso, 1848-1849), con diversas reediciones.

${ }^{95} \mathrm{Su}$ texto en Llobell, Joaquín - De León, Enrique - Navarrete, Jesús, cit. (n. 41), pp. 341-351. 
del nombre que había que dar a la nueva reglamentación del Derecho canónico y a las leyes particulares contenidas en ella. Aunque la tarea ya se había iniciado, uno y otro tema todavía suscitaban algunas dudas. Por lo que se refiere al nombre de este nuevo libro de leyes de la Iglesia, diversos cardenales entendían que el nuevo texto debía llamarse Codex, a efectos de reservar el nombre de Corpus a la colección de leyes que debería hacerse. Para otros cardenales era indiferente que se llamara Codex o Breviarium, y hubo quien insistió en que debía llamarse Breviarium o Promptuarium iuris canonici. En cuanto al nombre de las leyes particulares que debían incluirse en dicho texto, la mayoría estuvo por el término cánones en vez del de artículos, contra el parecer de los consultores ${ }^{96}$.

El 28 de junio de 1904 el Papa prestaba su aprobación al índice de materias, al que no se podrían introducir modificaciones; decidió también que la nueva colección recibiría el nombre de Codex y que las leyes particulares que se incluyeran en él se llamarían cánones; en caso de que éstos requirieran subdivisiones, serían llamadas parágrafos.

\section{Las reacciones frente a la codificación.}

La posibilidad de disponer dentro de un tiempo prudencial de una recopilación breve, clara y precisa de las leyes eclesiales vigentes no podía sino que suscitar alabanzas, especialmente entre quienes tenían que hacer uso cotidiano del Derecho canónico, como los párrocos, los rectores de seminarios o los administradores diocesanos. Pero la empresa no estaba exenta de dificultades y de ponerlas a la luz se encargaron algunos autores de la época que, tanto en revistas canonísticas como teológicas, escribieron numerosos artículos ${ }^{97}$ especialmente en los años 1905 y 1906, si bien este primer debate, en sus inicios, se circunscribió más bien a la canonística curial, pues la preparación doctrinal del resto de los autores no estaba adecuada a la codificación ${ }^{98}$.

Los dos autores que mostraron con más fuerza su perplejidad y escepticismo frente a la codificación del Derecho canónico fueron Francesco Ruffini (1863-1934) y Emil Friedberg (1837-1910), editor del Corpus Iuris Canonici, ambos profesores de Derecho en facultades de universidades estatales, fundados en la concepción que ambos tenían del Derecho

${ }^{96}$ Feliciani, Giorgio, Lineamenti, cit. (n. 54), p. 220.

${ }^{97}$ La bibliografía más completa en Hilling, N., Die Reformen des Papstes Pius $X$ auf dem Gebiete der kirchenrechtlichen Gesetzgebungs, en Archiv für katolisches Kirchenrecht 95 (1915), pp. 78-112. Se puede complementar con Astorri, R., Le leggi della Chiesa tra codificazione latina e diritti particolari (Padova, Cedam, 1993), p. 9.

${ }^{98}$ Falco, M., Introduzione allo Studio del 'codex iuris canonici' (Bologna, Il Mulino, 1992), p. 102. 
canónico, en el que la ley conservaba todavía algo de su primitivo carácter de pacto, a pesar de que el siglo XIX lo había mostrado cada vez más como un Derecho pontificio. Friedberg consideraba imposibles de superar las dificultades derivadas de la naturaleza del Derecho canónico, como el irresuelto problema de sus relaciones con la moral, la universalidad de su aplicación, que había superado el ámbito europeo, o el riesgo de perder una de las características típicas del Derecho de la Iglesia como era su elasticidad. Ruffini mostraba su perplejidad nada más hecho el anuncio de la codificación ${ }^{99}$, en tanto que Friedberg lo hacía cuando los trabajos codificadores estaban avanzados ${ }^{100}$, indicio de que los primeros ańos de trabajo de la comisión no había atenuado la perplejidad teórica o práctica avanzada al momento del anuncio del proyecto ${ }^{101}$.

En Francia, el decano de la Facultad de Derecho canónico de Paris, Augusto Boudinhon (+1941), que consideraba esta obra "extremadamente difícil y delicada" 102 , entendía que la dificultad estaba en combinar la unificación de la legislación con la variedad de condiciones donde se encuentra la Iglesia en las diversas regiones. Como el Derecho canónico estaba lejos de ser uniformemente observado en todas partes, cuando fuera codificado, ciertas partes de él llegarían a ser punto menos que imposible de practicar en algunos países. Era consciente que la codificación del Derecho era deseable, pero se preguntaba hasta que punto era posible y sabio llevarla adelante; si se podría hacer figurar en el Código algo diverso al Derecho común; en ese caso, qué hacer con las partes de ese Derecho común que no son observadas ni posible hacerlo en todos los países; si se estaría entonces forzados a hacer múltiple derogaciones al Derecho apenas promulgado para toda la Iglesia. Preguntas que se hacía no tanto para darles respuesta como para presentar el problema.

Otro autor italiano, Francesco Longoni ${ }^{103}$, que escribía el mismo año que Friedberg, entendía que la nueva codificación no estaba exenta de graves dificultades, entre otras, el que el siglo XIX había significado de hecho el ocaso de ciertos Derechos históricos y humanos gozados por la Iglesia por muchos siglos, creándole una posición de frente a la moderna sociedad

${ }^{99}$ Ruffini, Francesco, La codificazione del diritto canonico (Prato, 1904).

${ }^{100}$ Friedberg, Emil, Ein Neues Gesetzbuch für die katolisches Kirche, en Deutsche Zeitschrift für Kirchenrecht 8 (1908), pp. 1-74.

${ }^{101}$ Astorri, Romeo, La canonistica di fronte al CIC 17, en Cattaneo, Arturo (a cura di), L'eredita giuridica di san Pio X (Venecia, Marcianum Press, , 2006), p. 177.

${ }^{102}$ Le canoniste contemporain 28 (1905), pp. 80-81.

${ }^{103}$ Longoni, Francesco, La codificazione del diritto canonico, en La Scuola cattolica 36 (1908), p. 77. 
civil en la que no siempre podría quedar suficientemente resguardado lo que, por Derecho divino, compete a la sociedad cristiana.

En cambio, la canonística curial se movió en una línea pragmática, tratando de minimizar las dificultades teóricas, presentando la cuestión de la codificación como una consolidación del Derecho común que no tocaba para nada, al menos directamente, las costumbres locales, los estatutos sinodales de las diócesis, las constituciones de cada congregación religiosa, etc ${ }^{104}$.

La manualística de esos años no fue más entusiasta ${ }^{105}$. Francesco Ruffini volvió sobre el tema al publicar sus lecciones de Derecho eclesiástico ${ }^{106}$, manteniendo su escepticismo original. Juan Bautista Sagmüller (+1942) observaba en la edición de 1904 de su manual ${ }^{107}$, que la más reciente evolución de la legislación canónica y civil hacía renacer con mayor fuerza las antiguas reservas y, más aún, las reforzaba. El padre Wernz, por su parte, que participaba como consultor en las tareas codificadoras desde el primer momento, en la edición de 1913 de su Jus decretalium ${ }^{108}$ notaba que no raramente se había fuertemente exagerado la necesidad y la utilidad de una nueva codificación. Por su parte, Santi Romano ${ }^{109}$ dudaba en 1912 del buen resultado de la codificación, porque el Derecho canónico goza de su cualidad de Derecho tradicional y porque sería muy difícil poder distinguir cuales disposiciones antiguas deberían dejarse de lado y cuales, en cambio, conservarse y codificar. Y Schiappoli ${ }^{110}$ definía la codificación canónica como una empresa muy difícil por razones extrínsecas e intrínsecas, observando que no pocos canonistas, entre los que mencionaba a Ruffini y Friedberg, habían expresado dudas bien fundadas sobre la oportunidad y la utilidad de la codificación, así como sobre su buen resultado, especialmente en relación con los puntos contrastantes con los principios modernos.

\section{El trabajo de codificación.}

Dejando que los autores hicieran presente sus aprehensiones y sin

${ }^{104}$ Sulla codificazione del diritto canonico, en Rasegna giuridica ecclesiastica 2 (1904), 3, p. 274.

${ }^{105}$ Astorri, Romeo, cit. (n. 101), pp. 178-179.

${ }^{106}$ Ruffini, Francesco, Lezioni di diritto eclesiástico. a. a. 1911-12 (Torino, s.d.).

${ }^{107}$ SAGMüLLER, J. B., Lehrbuch des katolisches Kinchenrecht (Freiburg i/B, 1914), 3, p. 186.

${ }^{108}$ Wernz, F., Jus decretalium (3 ed., Romae, 1913), pp. 383-384.

${ }^{109}$ Romano, Santi, Lezioni di diritto ecclesiastico (Pisa, 1912), pp. 68-69.

${ }^{110}$ Schiappoli, D., Manuale di diritto ecclesiastico (Napoli, 1913). 
perjuicio de ellas, la comisión inicio sin retardo sus trabajos. Para hacer más eficientes los trabajos se instituyeron dos comisiones más reducidas; una de ellas llamada "juris substantivi", fue presidida por Pedro Gasparri y tuvo por secretario a Eugenio Pacelli quien, con el tiempo, sería Pío XII; la otra, llamada "juris adjectivi" tuvo por presidente al cardenal de Lai y por secretario a monseñor Sapieha. ¿Por donde empezar el trabajo? ¿Por el canon 1? En una carta del 31 de marzo de 1904, dirigida por Gasparri en los inicios mismos del trabajo codificador a los cardenales Ferrata, Vives y Tutó, Cavagnis y Gennari, a quienes se había pedido que organizaran el plan de trabajo, les comunicaba que el Papa, "sin imponer su voluntad", prefería que ante todo se abordara el tratado de sacramentos, después el de personas y los demás ${ }^{111}$.

Para redactar los proyectos de cánones se escogían diversos consultores para preparar un mismo proyecto. Los diversos redactores se ignoraban unos a otros y estaban obligados al secreto pontificio, si bien cada uno de ellos podía aportar sus ideas con toda independencia y seguros de que no habría indiscreciones. La elección de ellos como consultores dependía de su competencia particular. Al interior de las comisiones especiales ellos podían dar todas las explicaciones necesarias. Las diferentes proposiciones se completaban y corregían comparándolas unas con otras; después eran examinadas al interior de la comisión especial, donde eran discutidas y modificadas hasta llegar a una fórmula que era reconocida como satisfactoria, o simplemente eran eliminadas.

Las reuniones de las comisiones especiales se iniciaron el 13 de noviembre de 1904. Los consultores revisaban en la forma dicha los proyectos que habían sido elaborados. Después, el presidente, inspirándose en los textos y en las reflexiones suscitadas por ellos, redactaba un proyecto de conjunto, lo hacía imprimir y sobre el texto impreso se deliberaba en una nueva asamblea. El proyecto definitivo se redactaba cuando, sobre el proyecto redactado por el presidente, todos estaban de acuerdo. Considerando este método de trabajo, no hubo en el Código de 1917 ningún texto que no hubiese sido revisado y discutido cuatro o cinco veces; $y$, tratándose de cuestiones particularmente difíciles, diez o doce veces. Si no se lograba la unanimidad, se redactaba el texto siguiendo el parecer de la mayoría o siguiendo el Derecho en vigencia, pero poniendo cuidado de indicar cuál había sido la opinión de la minoría o qué modificaciones al Derecho se habían propuesto. Una vez que se había redactado, en la forma indicada, un proyecto en una comisión especial, era enviado a todos los consultores,

${ }^{111}$ Fantappie, Carlos, Pio $X$ e il Codex iuris canonici, en Cattaneo, Arturo, L'eredita giuridica di san Pio X (Venecia, Marcianum Press, 2006), p. 163. 
cada uno de los cuales debía, por escrito, redactar su opinión y hacerla llegar a monseńor Gasparri. El proyecto y las opiniones de los consultores eran estudiados por él quien hacía una relación a los cardenales de la comisión reducida respectiva quienes, después de dos exámenes, al menos, se pronunciaban sobre el texto propuesto.

En cuanto al contenido de las normas que se iban redactando y para evitar las dificultades y obstáculos señalados por algunos canonistas poco favorables a la codificación, se mantuvieron, con ciertas condiciones, los concordatos, los Derechos adquiridos, los privilegios, los indultos y las costumbres inmemoriales. Y para evitar dificultades diplomáticas, procuraron no tratar en un título especial el Derecho público de la Iglesia. De la misma manera se omitió el anuncio de grandes principios directivos como el de la superioridad de la Iglesia en las materias mixtas o la existencia de un poder indirecto que se puede ejercer a veces incluso en las cuestiones temporales. Más aún, tratándose de Derechos expresamente reivindicados, el Código abrió a veces la puerta a atenuaciones y a derogaciones para mantener los concordatos y el reconocimiento posible de algunas costumbres inmemoriales $^{112}$.

En la medida que el trabajo codificador iba avanzando, algunas de las reformas introducidas por la Comisión parecieron lo suficientemente útiles como adelantarlas en su vigencia, dando origen a diversas normas que, a manera de adelanto de lo que sería el Código, fueron apareciendo bajo el reinado de Pío $\mathrm{X}^{113}$. Para algún autor ${ }^{114}$ es difícil entender que, al

${ }^{112}$ Andrieu-Gritancourt, Pierre, cit. (n. 31), p. 885.

${ }^{113}$ Entre ellas está la constitución Sapienti Concilio en la que se reorganizó la curia romana, de 29 de junio de 1908, en AAS. 1, pp. 7-19 = Pii X Acta 4, pp. 146-161 = Fontes 3, cit. (n. 143), pp. 726-736, No682. La constitución Promulgandi, de 29 de septiembre de 1908, estableciendo el boletín Acta Apostolicae Sedis, como boletín oficial de la Santa Sede, en $A A S$. 1, pp. 5-6 = Fontes 3, pp. 750-751, o 684. La S. Congregación del Concilio había publicado antes, el 20 de diciembre de 1905, el decreto Sacra Tridentina Synodus acerca de la comunión frecuente, en ASS. 38, pp. 400-406 = Fontes 6, pp. 828-831, No 4326; y el 2 de agosto de 1907, el famoso decreto Ne temere, sobre el matrimonio, en $A S S .40$, pp. 525-530 = Fontes 6, pp. 867-870. Por su parte, la $S$. Congregación consistorial publicó el 31 de diciembre de 1909 el decreto $A$ remotísima concerniente a la visita ad limina apostolorum, en AAS. 2, pp. 13-16 = Fontes 5, pp. 14-17, No 2064; y el no menos famoso decreto Maxima cura, de 20 de agosto de 1910 sobre el traslado administrativo de los curas, en $A A S$. 2, pp. 636-648 = Fontes 5, pp. 35-44, No 2074. La S. Congregación de sacramentos, publicaba el 8 de agosto de 1910 el decreto Quam singulari, sobre la edad de la primera comunión, en $A A S$. 2, pp. 577$583=$ Fontes 5 , pp. 80-85. № 2103. Y la S. Congregación de religiosos el decreto Cum singulae, de 16 de mayo de 1911 sobre la expulsión y dimisión de religiosos, en $A A S$. 3, pp. $235-238$ = Fontes 4, pp. 1011-1014, No 4409 .

${ }^{114}$ Vetulani, A., cit. (n. 85), col. 926. 
momento de su publicación, todas estas leyes fuesen indispensables para el bien de la Iglesia, por lo que es probable que a veces se las publicara antes de incorporar nuevas prescripciones en el texto del Código a fin de ver su eficacia en la vida práctica, y saber cómo serían acogidas por los medios eclesiásticos y los Estados.

Durante trece ańos se trabajó arduamente, revisando con detalle una masa impresionante de documentos que se había ido acumulando desde el siglo XVI; casi seiscientos años de leyes, decretos, cánones, costumbres y usos debieron ser inventariados, clasificados, examinados, comparados $\mathrm{y}$ escogidos en función de su vigencia y utilidad.

\section{Las sucesivas consultas a los obispos.}

El proceso de codificación siguió su desarrollo con el trabajo de elaboración de proyectos parciales los que, una vez terminados, dieron origen a una nueva consulta al episcopado de todo el mundo. Dicha consulta, que se hizo entre los años 1912 y 1914, contó con la oposición de algunos cardenales ${ }^{115}$, pero fue autorizada expresamente por san Pío X y se hizo enviando los distintos proyectos parciales a todos los obispos y prelados de la Iglesia latina que, de acuerdo con los cánones vigentes, hubiesen debido ser convocados a un eventual Concilio Ecuménico, incluidos los vicarios y prefectos apostólicos.

Por medio de una carta circular firmada por el cardenal Pedro Gasparri, presidente de la comisión codificadora, fechada el 20 de marzo de 1912, se envió a los obispos y a los superiores generales de las órdenes religiosas el proyecto de Libro primero, Normae generales, y del Libro segundo, De personis ${ }^{116}$. Según las instrucciones que se daba a los obispos en dicha circular, podían proceder al examen de los cánones contenidos en cada uno de los dos proyectos valiéndose de tres expertos en Derecho canónico, clérigos regulares o seculares, pero, tanto los obispos como los consultores quedaban obligados al secreto pontificio; las observaciones debían ser enviadas a la Santa Sede no más allá de los seis meses de haber recibido el proyecto. Un año después, el 1 de abril de 1913, se envió el Libro tercero,

${ }^{115}$ Entendían que el envío de los ejemplares, la espera de las respuestas de los obispos y el análisis de las mismas retrasarían la promulgación del Código.

${ }_{116}$ (Schema Codicis Iuris Canonici)/ (Sub secreto pontificio)/ Sanctissimi Domini Nostril Pii PP. X/ Codex Iuris Canonicil cum notis/ Petri card. Gasparril [escudo pontificio de Pío X]/ Romael Typis polyglottis Vaticanis/MDCCCCXII/, 281 pp. El libro I lo componían 79 cánones y el II 567 cánones. ASV. CIC 17, scat. 23. 
De rebus ${ }^{117}$, anunciándose el envío del Libro cuarto, De delictis et poenis ${ }^{118}$, y del Libro quinto, De iudicis ecclesiasticis ${ }^{119}$, que les serían transmitidos, respectivamente, el 1 de julio de 1913 y el 15 de noviembre de 1914 . La numeración de los cánones no era única y continua para todos estos proyectos parciales, sino que se iniciaba en cada uno de los volúmenes. Y todos ellos, con excepción del quinto, llevaban, a pie de página, notas en las que se individualizaban la o las fuentes de donde había sido tomado el respectivo canon; según se indicaba en la portada de cada uno de estos volúmenes, ellas correspondían al cardenal Gasparri. La falta de notas en el último de los libros se decidió para acelerar los trabajos de impresión y distribución y no porque se considerasen poco útiles.

Las respuestas enviadas en esta oportunidad por los obispos, los ordinarios y los superiores religiosos consultados dieron origen a las Animadversiones Episcoporum u observaciones de los obispos a los diversos proyectos parciales de Código de Derecho Canónico elaborados por la comisión de codificación. Las Animadversiones, nada más llegar a Roma, eran clasificadas y ordenadas según la numeración que tenían los cánones respectivos en los proyectos. Algunas de estas observaciones fueron enviadas por los obispos individualmente, otras conjuntamente con los demás obispos de la provincia eclesiástica y su metropolitano. Y como había sucedido con los Postulata, ahora las Animadversiones fueron igualmente impresas en textos que, al igual que había sucedido la primera vez, permanecieron en estricta reserva.

La idea de haber sometido los proyectos a las observaciones del episcopado, al final, se reveló feliz y fecunda. De hecho las diferencias entre los proyectos y el texto finalmente publicado no son de mera forma, sino que son más importantes y profundas ${ }^{120}$.

117 (Schema Codicis Iuris Canonici)/ (Sub secreto pontificio)/ Sanctissimi Domini Nostril Pii PP. X/ Codex Iuris Canonicil cum notis/ Petri card. Gasparri/ [escudo pontificio de Pío X]/ Romael Typis Polyglottis Vaticanis/MDCCCCXIII/, 365. pp., y 831 cánones. ASV. CIC 17, scat. 51.

118 (Schema Codicis Iuris Canonici)/ (Sub secreto pontificio)/ Sanctissimi Domini Nostril Pii PP. X/ Codex Iuris Canonicil cum notis/ Petri card. Gasparri/ [escudo pontificio de Pío X]/ Romael Typis Polyglottis Vaticanis/ MDCCCCXIII/, 106 pp., y 227 cánones. ASV. CIC 17, scat. 79.

${ }^{119}$ (Schema Codicis Iuris Canonici)/ (Sub secreto pontificio)/ Codex Iuris Canonicil cum notis/ Petri card. Gasparri/ [escudo pontificio de Benedicto XV]/ Romael Typis Polyglottis Vaticanis/ MDCCCCXIVI, 238 pp., y 773 cánones. ASV. CIC 17, scat. 70.

${ }^{120}$ Un primer análisis en lo que se refiere al Derecho matrimonial en VetUlani, A., cit. (n. 85), col. 930-933, donde se identifica una larga y significativa lista de cánones agregados al proyecto de 1912, además de otros que fueron suprimidos. 
Hacia junio de 1914 se trabajaba en el proyecto de constitución con la cual el Papa podría haber promulgado el Código en los primeros días de 1915. Sin embargo, el estallido de la primera Guerra Mundial y la muerte de Pío X (20 agosto 1914) retrasó en un par de años la promulgación del codex $^{121}$. A Pío X le sucedió en el trono pontificio Benedicto XV quien, desde su elevación al pontificado había manifestado su decisión de terminar la tarea iniciada por su predecesor. El aplazamiento del proyecto, no obstante que el trabajo ya estaba terminado hizo que el nuevo Papa, como ya lo había hecho su antecesor, promulgara algunos decretos que parecen anticipos del Código que estaba pronto a terminar: entre ellos se pueden mencionar el quirógrafo Atentis expositi, de 28 de junio de $1915^{122}$, relativo a la Signatura Apostólica; el motu proprio Seminaria, de 4 de noviembre de $1915^{123}$, sobre la S. Congregación de seminarios y universidades; el motu proprio Alloquentes proxime, de 25 de marzo de $1917^{124}$ sobre la supresión del Index, la atribución de la censura de libros al Santo Oficio y la atribución de la concesión de indulgencias a la Sagrada Penitenciaría; el motu proprio Dei providentis, de 1 de mayo de $1917^{125}$ instituyendo la Congregación para las iglesias orientales.

\section{EL “CODEX IURIS CANONICI"}

\section{La promulgación del "Codex".}

El 27 de mayo de 1917, festividad de Pentecostés, el Papa Benedicto XV, mediante la constitución apostólica Providentísima mater Ecclesia promulgó el Código de Derecho Canónico ${ }^{126}$. Utilizando categorías del Derecho público eclesiástico de la época, el Papa parte afirmando que la "Providentísima Madre Iglesia" había sido dotada por su divino fundador "de todas las notas que convienen a cualquier sociedad perfecta", por lo que, desde sus inicios, la Iglesia había empezado "a regular y defender por medio de leyes la disciplina del clero y del pueblo cristiano". Después de un breve repaso histórico, el Papa recordaba las palabras de su antecesor que mostraban el estado complejo al que había llegado el Derecho canónico por la acumulación de leyes a lo largo de los siglos, las que "habian llegado a ser tan numerosas y se hallaban tan desparramadas y dispersas, que muchas de ellas eran desconocidas no sólo

${ }^{121}$ Motilla, Agustín, cit. (n. 8), p. 706.

${ }^{122}$ AAS. 7, pp. 320-325 = Fontes 3, pp. 848-851, No 705.

${ }^{123} A A S .7$, pp. 493-495 = Fontes 3, pp. 855-856, No 708.

${ }^{124} A A S .9$ (1917), p. 167.

${ }^{125}$ AAS. 9 (1917), pp. 529-531.

${ }^{126}$ Su texto en $A A S .9$ (1917), pp. 5-8; también en OcноA, Xaverius (ed.), Leges Ecclesiae post Codicem iuris canonici editae (Roma, 1966), I, col. 60-60. 
del vulgo, sino hasta de las personas más peritas", razón por la que había dado inicio a la tarea de elaborar un nuevo Código, de cuyos trabajos hacía una breve reseńa. Finalmente, "invocando el auxilio de la gracia divina, contando con la autoridad de los Santos Apóstoles Pedro y Pablo, de motu proprio, con conocimiento cierto y en virtud de la plenitud de la potestad Apostólica de la que estamos investido, por esta Nuestra Constitución, que queremos esté siempre en vigor, promulgamos el presente Código, tal cual está ordenado, y decretamos y mandamos que en adelante tenga fuerza de ley en toda la Iglesia y lo encomendamos a vuestra custodia y vigilancia para que sea observado".

En la misma constitución disponía que "para que todos aquellos a quienes corresponde puedan conocer bien los preceptos de este Código antes de ser aplicados", la entrada en vigencia del mismo sería el día de Pentecostés del año 1918, esto es, el 19 de mayo de ese año ${ }^{127}$. Sin embargo, el Papa, ante la petición de numerosos obispos, dispuso el 20 de agosto de $1917^{128}$ la inmediata aplicación de diversas normas codiciales: las concernientes a los privilegios de los cardenales; los poderes de los obispos para anticipar o prorrogar el tiempo pascual y de permitir, incluso en adviento y cuaresma, la bendición nupcial; el nuevo catálogo de fiestas de precepto; las reglas concernientes al ayuno y abstinencia.

La edición oficial del Código se hizo el 28 de junio de 1917 en los Acta Apostolicae Sedis, con el siguiente título ${ }^{129}$ : Codex Iuris Canonici Pii $X$ Pontificis Maximi iussu digestus Benedicti Papae XV auctoritate promulgatus. Con el mismo título se hizo una primera edición el año 1917 de 582 páginas en la que, además del Código, se incluían otros documentos y materiales para su mejor uso. En efecto, después del título ${ }^{130}$ se incluía

${ }^{127}$ La constitución finaliza con la tradicional y solemne fórmula según la cual "a nadie, pues, le será lícito infringir u oponerse temerariamente a esta página de Nuestra Constitución, ordenación, limitación, supresión, derogación y voluntad de cualquier modo expresada. Si alguno tuviere la osadía de intentarlo, sepa que incurrirá en la indignación de Dios todopoderoso y de sus Santos Apóstoles Pedro y Pablo".

${ }^{128}$ Decreto Episcopi aliive locoroum, en AAS. 9 (1917), p. 475 = ОсноА, cit. (n. 126), I, col. 89-90.

${ }^{129} \mathrm{El}$ mismo día 28 de junio de 1918 se celebró solemnemente en el Vaticano la promulgación del Codex, en presencia de numerosos cardenales, arzobispos y obispos. Al mismo tiempo se mandó a acuñar una medalla conmemorativa que llevaba en el recto el retrato del pontífice reinante con la leyenda "Benedictus Pont. Max. A. IIr", haciendo alusión al tercer ańo de pontificado del Papa; y en el reverso se representa al Papa sentado sobre su trono, mostrando a quienes le rodean el nuevo Código con la leyenda "Novo Ecclesiae legum codice publicato".

${ }^{130}$ Codex/ Iuris Canonicil Pii X Pontificis Maximil iussu digestus/ Benedicti Papae XV/ auctoritate promulgatus/ [escudo de Benedicto XV]/ Romael Typis Polyglottis Vaticanis/ MCMXVII/. 
un largo Praefatio redactado por el cardenal Gasparri, al que le seguía el texto de la constitución apostólica Providentissima Mater Ecclesiae, con la que se había promulgado el Código, y la Professio Catholicae Fidei. Venían después los 2414 cánones que integraban el Codex, que eran seguidos por una serie de ocho Documenta que eran mencionados en algunos cánones del nuevo Código ${ }^{131}$. Siguiendo a dichos documentos venía una tabla de Corrigenda et addenda, a la que seguía el motu proprio Cum iuris canonici, con el que Benedicto XV había instituido una comisión para la interpretación auténtica del Código; un Index Analytico-alphabeticus elaborado por el cardenal Gasparri y, finalmente, el Index voluminis. Al año siguiente, 1918, se publicó otra edición oficial en la que se incorporaron al pie de página las citas de las fuentes de donde se habían obtenido los contenidos de los cánones, hecha por el cardenal Gasparri ${ }^{132}$. El contenido de este nuevo ejemplar del Código, sin contar las notas de fuentes, era similar al de la edición de 1917, si bien se eliminaba la tabla de correcciones y adiciones, las que habían sido incorporadas en esta nueva edición.

\section{Una valoración de conjunto del "Codex".}

El simple enunciado del contenido del Codex permite advertir una de las notas del texto codicial: en un solo Código se regulaba lo que en los Derechos estatales era objeto de varios. Otra nota significativa fue que el Código no hizo tabla rasa del Derecho anterior; él mismo señalaba en su

${ }^{131}$ i) Constitución Vacante Sede Apostolica, de Pío X, de 25 de diciembre de 1904, sobre el gobierno de la Iglesia después de fallecido un Papa y el procedimiento para la elección de su sucesor, mencionada en el canon 160; ii) constitución Commissum Nobis, de Pío X, de 20 de enero de 1904; iii) Constitución Praedecesores Nostri, de León XIII, de 24 de mayo de 1882; iv) constitución Cum illud, de Benedicto XIV, de 14 de diciembre de 1742, que reglamenta los concursos especiales a parroquias reglados en el canon $459 \$ 4$ del Código, en el que se hace expresa referencia a esta constitución; v) constitución Sacramentum poenitentiae, de Benedicto XIV, de 1 de junio de 1741, sobre el delito de solicitación en confesión, mencionada en el canon 904; vi) una parte de la constitución Altitudo, de Paulo III, de 1 de junio de 1537, sobre la situación de los matrimonios polígamos, o con parientes, de los indios americanos y de lo que hay que hacer para recibir el bautismo, mencionada en el canon 1125; vii) constitución Romani Pontificis, de san Pío V, de 2 de agosto de 1571, complementando la anterior, mencionada en el mismo canon 1125; viii) constitución Populis, de Gregorio XIII, de 25 de enero de 1585, sobre el matrimonio de los esclavos bautizados, mencionada también en el mismo canon 1125.

${ }^{132}$ Codex/ Iuris Canonicil Pii X Pontificis Maximil iussu digestus/ Benedicti Papae $X V /$ auctoritate promulgatus/ Praefatione, Fontium annotationel et Indice Analyticoalphabetico/ ab Emo./ Petro card. Gasparril auctus/ Romael Typis Polyglottis Vaticanis/ MCMXVIIII, $784 \mathrm{pp}$. Todo el título aparece enmarcado en una orla que en su parte inferior tiene el escudo del Papa Benedicto XV. 
canon 6 que "el Código conserva en la mayoría de los casos la disciplina hasta ahora vigente, aunque no deja de introducir oportunas variaciones". De allí que "en la duda de si alguna prescripción de los cánones discrepa del Derecho antiguo, no hay que separarse de éste" (canon $6 \mathrm{n}^{\circ}$ 4). Fue éste, sin duda, uno de sus méritos, pero fue quizá su mayor debilidad.

En efecto, el Código de 1917 nació mirando al pasado, en momentos en que las circunstancias históricas se sucedían con una rapidez hasta entonces desconocida. No fue necesario que pasaran muchos años para que esto se hiciera sentir. Problema de vejez que se acentuó con otro, el del inmovilismo. Como lo ha señalado Lombardía ${ }^{133}$, el Código se aplicó desconectado de su tradición histórica por una doctrina que rara vez se atrevió a llevar a cabo una interpretación progresiva y por una jurisprudencia que, salvo las materias matrimoniales, estuvo privada de acción actualizadora. En este sentido, el Codex fue como una gran disposición administrativa, con la agravante de ser aplicada sin control contencioso administrativo. Esta aplicación burocrática originó su propia ruina. "Las estructuras oficiales por él previstas para dar cauce a la acción pastoral de la Iglesia, cuando necesitaban ser actualizadas por el cambio de circunstancias, se conservaban fosilizadas [...] mientras surgían paralelamente un conjunto de estructuras escasamente regladas, a través de las cuales se desenvolvía la actividad pastoral, al margen de cualquier ordenación jurídica”.

Se le criticó también la cultura teológica y eclesiológica subyacente, que habría producido, entre otros, el efecto de producir un exceso de juridicismo en la vida de la Iglesia. En efecto, por un lado, el Código señalaría el punto de máxima separación entre Derecho y teología, entre Derecho y moral, expresando un singular e inesperado proceso de secularización del Derecho de la Iglesia que, contra toda intención, lo habría acercado a la sospechosa cultura de la modernidad. Por otro lado, el Código sería expresión de una eclesiología en la que se advierte un cierto desequilibrio en las relaciones entre la iglesia universal y las iglesias particulares, entre primado y colegialidad; en otras palabras, sería funcional a un diseño de concentración que, a través de una rígida uniformidad disciplinar, termina por negar todo legítimo pluralismo en la Iglesia, favoreciendo un juridicismo que reduce la adaptabilidad -elasticidad-típica del Derecho canónico ${ }^{134}$.

Desde el punto de vista de la cultura jurídica, el Código habría repre-

${ }^{133}$ Hervada, Javier - Lombardía, Pedro, El Derecho del Pueblo de Dios. Hacia un sistema de Derecho canónico, I: Introducción. La constitución de la Iglesia (Pamplona, 1970), pp. 132-133.

${ }^{134}$ Dalla Torre, Giuseppe, Il Codice di Diritto Canonico, en La Bella, Gianni (a cura di), Pio Xe il suo tempo (Bologna, Il Mulino, 2003), p. 321. 
sentado el fruto de un largo proceso de asimilación de la Iglesia al Estado, en el contexto de una concepción secularizadora de la Iglesia como societas iuridice perfecta, congruente con el planteamiento de san Roberto Belarmino para quien la Iglesia era una sociedad tan visible y palpable como el reino de Francia o la república de Venecia ${ }^{135}$. Perspectiva ésta en la que igualmente se pone de relieve el papel del Código en la secularización de la Iglesia.

Incluso, los vacíos y lagunas del Código fueron igualmente criticados, algunos particularmente graves como la poca atención dada al laicado, ignorando incluso fenómenos eclesiales vigorosos al momento de la promulgación del Código como la acción católica.

No obstante lo anterior, siguiendo dos voces autorizadas, el Código "significó una nueva era en la historia del Derecho canónico y de la Iglesia, y un paso gigantesco sobre el ordenamiento que entonces estaba vigente" 136 . Además, consiguió cumplir "el fundamental objetivo que se propusieron sus redactores: es decir, dotar a la estructura oficial de la Iglesia de unas normas claras de actuación, mediante el expediente de determinar con bastante exactitud las atribuciones y responsabilidades de los oficios de la organización eclesiástica"137.

Por otra parte, si bien se ha criticado la eventual secularización del Derecho de la Iglesia, crítica por lo demás discutible, ello habría ocurrido en un plano meramente formal, pero no habría incidido en el contenido de las normas. En ellas, por el contrario, se advierte una suerte de es p i r i t u a li za ción en el sentido de verse liberado el Derecho de la Iglesia no sólo de los residuos normativos que históricamente se habían ido estableciendo en razón de la soberanía temporal de los papas, sino también de la formalización de normas propiamente canónicas pero pensadas y escritas en el contexto de una soberanía que al mismo tiempo era espiritual y temporal. Desde esta perspectiva el Código aparece plenamente en línea con el sentido espiritual, religioso y eclesial del pontificado de Pío X, cuyo programa de gobierno, señalado desde el inicio del mismo, fue Instaurare omnia in Christo. Un pontificado caracterizado por una fuerte tensión ideal, una intransigencia en los principios, una profunda piedad y una preeminente preocupación pastoral debía encontrar

135 "Ecclesia enim est coetus hominum ita visibilis et palpabilis, ut est coetus populi Romani, vel Regnum Galliae, aut respublica Venetorum", en De controversiis christianae fidei adversus huius temporis haereticos (Coloniae Agrippinae, 1615), p. 44.

${ }^{136}$ García y García, Antonio, Las codificaciones y su impacto en la Iglesia a través de la historia, en Temas fundamentales en el Nuevo Código. XVIII Semana de Derecho Canónico (Salamanca, 1984), ahora en El Mismo, Iglesia, sociedad y Derecho (Salamanca, 1987), II, p. 270.

${ }^{137}$ Hervada, Javier; Lombardía, Pedro, cit. (n. 133), p. 132. 
en el Código un instrumento práctico de realización ${ }^{138}$.

Nunca en la historia del Derecho canónico un texto había asumido el Derecho anterior dejando a las colecciones anteriores sin vigencia, como sucedió en 1917. A partir de ese momento, las colecciones que se habían acumulado durante siglos pasaron a tener importancia principalmente histórica, aun cuando siguieron siendo fuente subsidiaria del Derecho, especialmente interpretativa. La codificación sirvió para separar con rigidez historia y Derecho. Pero no deja de ser paradójico que el pontificado de san Pío X, que se distinguió por su rigor antimodernista, haya dado el empuje y el sostén para que en el seno de la propia Iglesia se recibiera uno de los productos típicos de la modernidad y del Estado moderno: la codificación del Derecho ${ }^{139}$. Una nueva demostración de cómo la Iglesia, con su Derecho, no sólo ha sido capaz de ceder valores a la sociedad civil y de contribuir así al progreso de ésta, sino que también está abierta a la recepción de lo bueno que la experiencia de la sociedad civil está en grado de hacer emerger en el devenir de la historia ${ }^{140}$.

\section{Las "Fuentes" de Gasparri.}

Ya sabemos que por circular de 6 de abril de 1904 atribuible al secretario de la Comisión, Pedro Gasparri, dirigida a los rectores de las universidades católicas para pedirles el concurso "en esta empresa importante y difícil" ${ }^{141}$, se afirmaba la intención del Papa de "distribuir metódicamente todo el Derecho canónico en cánones o artículos, a la manera de los códigos modernos y, al mismo tiempo, de hacer una recopilación de todos los documentos aparecidos después de las colecciones auténticas del Corpus Iuris de las que dichos cánones o artículos deberán ser tomados". Sabemos también que en el reglamento de la comisión se disponía que en la compilación de los cánones o artículos los consultores debían conservar, en la medida de lo posible, las palabras de los documentos de las que eran extraídas, las que debía ir entre comillas ("), cuidando al mismo tiempo la brevedad y la claridad, indicando en cada caso la página, el volumen y la edición del documento del cual eran extraídos (artículo 8); y que uno o más consultores nombrados por el secretario tendrían el encargo de anotar los documentos de los cuales eran extraídos dichos cánones o artículos, con excepción de los que provenían del Corpus Iuris Canonici o del Concilio de Trento (artículo 9). Se encuentra

\footnotetext{
${ }^{138}$ Dalla Torre, Giuseppe, cit. (n. 134), p. 325.

${ }^{139}$ Turchi, V., Le disposizioni preliminari sul matrimonio nel processo di codificazione piano-benedittino (Torino, 2000), p. 56.

${ }^{140}$ Le Bras, Gabriel, La Chiesa del diritto. Introduzzione allo studio delle istituzioni ecclesiastiche (Bologna, 1976), p. 46.

${ }^{141}$ Circular Perlegisti, en ASS. 37 (1904-1905), pp. 130-131.
} 
aquí el punto de partida de lo que, años después, serían los nueve gruesos volúmenes que, publicados en forma privada por Gasparri con la colaboración de Seredi, constituyeron la colección de fuentes del Código de 1917, en la que se incluía el texto completo de las fuentes que aparecían indicadas en la edición anotada del Código de Derecho Canónico publicada por la editorial vaticana en $1918^{142}$. Estas fuentes, sin embargo, no formaban parte oficial del Código, conservando el cardenal Gasparri la propiedad intelectual de ese trabajo así como el del índice analítico-alfabético ${ }^{143}$. A partir del séptimo volumen las Fuentes fueron publicadas por el cardenal Seredi ${ }^{144}$. El noveno y último volumen recoge los índices.

\section{El fondo documental de la codificación de 1917.}

Concluida la tarea codificadora, el fondo documental originado con ocasión de la misma, y que estaba previsto en el reglamento de la Comisión codificadora, permaneció por años en el archivo de la Secretaría de Estado proveniente de la Sagrada Congregación para los asuntos eclesiásticos extraordinarios, que llegó a ser, con el tiempo, la Sección segunda de la Secretaría de Estado, dicasterio del que dependió la Comisión codificadora cuando fue creada en 1904. Cuando, en 1963, se inició la revisión del Código de Derecho Canónico de 1917, tarea que dio origen al Código de Derecho Canónico de 1983 en actual vigencia, aquel rico material fue transferido a la Pontificia comisión para la revisión del Código de Derecho Canónico, para que pudiera ser utilizado por ésta. Finalizado, a su vez, el trabajo de codificación del Codex de 1983, el fondo documental del

\footnotetext{
${ }^{142}$ Véase antes n. 132.
}

${ }^{143}$ Gasparri, card. Petri (a cura di), Codicis Iuris Canonici Fontes, I: Concilia generalia; Romani Pontifices usque ad annum 1745 (Typis Poliglottis Vaticanis, Romae, 1947); II: Romani Pontifices A. 1746-1865 (Typis Poliglottis Vaticanis, 1948); III: Romani Pontifices A. 1867-1917 (Typis Poliglottis Vaticanis, 1933); IV: Curia Romana, S.C.S. Off., S. C. Ep. et Reg. (Typis Poliglottis Vaticanis, 1941); V: Curia Romana, S. C. Consit., S. C. de Sacramentis, S. C. C. A. 1573-1760 (Typis Poliglottis Vaticanis, 1941); VI: Curia Romana, S. C. Concilii, an. 1761-1917, S. C. Super Statu Regul., S. C. de Religiosis (Typis Poliglottis Vaticanis, 1962); VII: Curia Romana, S. C. de Propaganda Fide, S. C. Indulg., S. C. Indicis, S. R. C., an. 1588-1790 (Typis Poliglottis Vaticanis, 1955); VIII: Iustiniani card. SEREdi (cura et studio), Curia Romana, S. R. C., an. 1804-1917; SS. CC., Caerme. Neg. Eccl. Extr., Stud. Semen., Poenit. Ap., Secr. Stat., Secre. Brev., Reg. Curiae Rom., Vicar. Urb. (Typis Poliglottis Vaticanis, 1938); IX: Tabellae (Typis Poliglottis Vaticanis, 1939).

${ }^{144} \mathrm{~A}$ decir verdad, aunque los seis primeros volúmenes fueron publicados bajo el nombre de Gasparri, "se sabe bien que fueron obra de un precioso y umbrátil benedictino, el cardenal húngaro Seredi”. Prof. Fantappie, Interventi nella tavola rotonda, en Cattaneo, Arturo, L'eredita giuridica di san Pio X (Venecia, Marcianum Press, 2006), p. 337. 
Código de 1917 fue enviado al Archivo Secreto Vaticano, integrado por 98 legajos $^{145}$.

Por decisión de Juan Pablo II, el año $1985^{146}$ fue autorizada la consulta de los fondos guardados en el Archivo Secreto Vaticano hasta la conclusión del pontificado de Benedicto XV (1922), decisión que ha permitido desde esa fecha poder acceder a los fondos referidos a la codificación del Derecho canónico de 1917 y, por lo mismo conocer la intervención que en ella le cupo a los obispos chilenos ${ }^{147}$. Dichos fondos han de complementarse con el Fondo Doppioni, relativo a la codificación de 1917, consistente en 33 legajos; y con el llamado Fondo CIC-Roberti, también referido a la misma codificación y que consiste en ocho carpetas de documentos diversos. Estos dos últimos se encuentran igualmente en el Archivo Secreto Vaticano.

[Recibido el 21 de febrero y aceptado el 5 de mayo 2008].

\section{BIBLIOGRAFÍA}

Boudinhon, A., L'opera di Pio X nella legislazione canonica (Treviso, 1916).

Cataneo, Arturo (a cura di), L'eredità giuridica di san Pio X (Venecia, Marcianum Press, 2006).

Ciprotti, Pio, Codex Iuris Canonici, en Enciclopedia del Diritto (Milano, 1960), VII, pp. 236-240.

Dalla Torre, Giuseppe, Il Codice di Diritto Canonico, en La Bella, Gianni (a cura di), Pio Xe il suo tempo (Bologna, Il Mulino, 2003), pp. 311-332.

DE Echeverría, Lamberto, La codificación del Derecho canónico vista en España a fines del siglo XIX, en Apollinaris 33 (1960): Miscellanea in memoriam Petri card. Gasparri, pp. 327-341,

Falco, Mario, La codificazione del diritto canonico (Milano, 1921).

Falco, Mario, Introduzione allo studio del Codex Iuris Canonici (Milano, 1925; Bologna, 1992), pp. 81-122.

Falco, Mario, Il Codex Iuris Canonici e il diritto anteriore, en Archivio Giuridico 90 (1923), pp. 13-27.

Falco, Mario, Codex Iuris Canonici, en Novissimo Digesto Italiano (Torino, 1959), III, pp. 380-381.

FANTAPPIÈ, Carlo, Gl'inizi della codificazione pio-benedettina alla luce di nuovi documenti, en Il Diritto Ecclesiastico 113 (2002), I, pp. 16-71.

\footnotetext{
${ }^{145}$ Llobell, Joaquín - de León, Enrique - Navarrete, Jesús, cit. (n. 41), pp. $1-3$.

${ }^{146}$ AAS. 78 (1986), p. 378.

${ }^{147}$ Archivo Secreto Vaticano, Commissione (Pontificia) per la codificazione del Diritto Canonico, Indice 1164. Se puede consultar Archivo Secreto Vaticano, Indice de los Fondos y relativos instrumentos de descripción de investigación (Ciudad del Vaticano, 2004-2005).
} 
Farret, A., Compilation ou codification? Relecture, un siècle après, du Canoniste Contemporain, en L'anné canonique 38 (1996), pp. 305-317.

Feliciani, Giorgio, Il Concilio Vaticano I e la codificazione del diritto canonico, publicado con variantes en: La norma en el Derecho canónico. Actas del III Congreso internacional de Derecho canónico. Pamplona 10 a 15 de octubre de 1976 (Pamplona, 1979), I, pp. 505-525; Ephemerides Iuris Canonici 33 (1977), pp. 115-143; 269-289; Studi in onore di Ugo Gualazzini (Milano, 1982), II, 35-80.

Feliciani, Giorgio, Presentazione, al libro de Vismara, M. - Missiroli - Musselli, L., Il proceso di codificazione del diritto penale canonico (Padova, 1983), pp. 3-23.

Feliciani, Giorgio, Mario Falco e la codificaciones del diritto canonico, en Falco, Mario, Introduzione allo studio del Codex iuris Canonico (ed. a cura di Giorgio Feliciani, Bologna, 1992), pp. 13-35.

Feliciani, Giorgio, Gasparri et le droit de la codification, en L'Anné Canonique 38 (1996), pp. 25-37 = Studi in onore di Gaetano Catalana (Soveria Mannelli, 1998), II, pp. 563ss.

Finocchiaro, F., Il processo di codificazione del diritto canonico, en Anuario di diritto comparato e di studi legislativi 44 (1970), pp. 181-198.

Gasparri, Petrus, Storia della codificazione del diritto canonico por la Chiesa latina, en Pontificium Institutum Utriusque Iuris, Acta congressus iuridici internationalis. VII saeculo a Decretalibus Gregorii IX et XIV a Codice Iustiniano promulgatis (Romae, 1937), IV, pp. 4-10.

Grossi, Paolo, Storia della canonistica moderna e storia della codificazione canonica, en Quaderni fiorentini per la storia del pensiero giuridico moderno (1985), pp. 587 ss.

Hervada, Javier - Lombardía, Pedro, El Derecho del Pueblo de Dios. Hacia un sistema de Derecho canónico, I: Introducción. La constitución de la Iglesia (Pamplona, 1970).

KuTtNer, Stephan, Il diritto canonico nella storia, en Ius 18 (1967), pp. 241-

KutTner, Stephan, The Code of Canon Law in historical perspective, en The Jurist 28 (1968), pp. 132 ss.

Kuttner, Stephan, Il Codice di Diritto Canonico nella storia, en AA.VV., Commemorazione del cinquantesimo anniversario della promulgazione del Codex Iuris Canonici (Romae, 1967), pp. 17-39 = Apollinaris 40 (1967), pp. 9-25.

Le Bras, Gabriel, La Chiesa del diritto. Introduzzione allo studio delle istituzioni ecclesiastiche (Bologna, 1976),

Llobell, Joaquín - De León, Enrique - Navarrete, Jesús, Il libro "De processibus" nella codificazione del 1917. Studi e documenti (Milano, Giuffré, 1999), I.

Motilla, Agustín, La idea de la codificación en el proceso de formación del Codex de 1917, en Ius Canonicum 28 (1988), 56, pp. 681-720.

Noval, I., Codificationis iuris canonici recensio historico-apologetica et codicis benedictinis notitia generalis: doctrina al studium novi codicis propedéutica (Roma, 1918).

Noval, I., El Código de Derecho Canónico, en La Ciencia Tomista 17 (1918), pp. 176-184.

Piola, A., Sulla commemorazione cinquantenaria del Codex Iuris Canonici, en Annali della Facoltà di Giurisprudenza. Università degli Studi di Genova 6 (1967), pp. 229-233.

Postius, J., El código canónico (Barcelona, 1918), pp. 23-75.

Ruffini, Francesco, La codificazione del diritto ecclesiastico, en Ruffini, Franceso, Scritti giuridici minore (Scelti e ordinati da M. Falco, A. C. Jemolo, E. Ruffini). 
Scritti di Dir. ecclesiástico (Milano, 1936), I, pp. 70 ss.

Staffa, D., Codex Iuris Canonici, en Enciclopedia Cattolica (Roma, 1953), III, pp. 200-205.

StIKLER, Alphonsus Maria, Historia iuris canonici latini. Institutiones academicae, 1: Historia fontium (Augustae Taurinorum, 1950), pp. 371-384.

van Hove, Alphons, Prolegomena, en Commentarium lovaniense in Codicem Iuris Canonici I (Michliniae-Romae, 1945), I, pp. 613-619.

Ventulani, A., Codex juris canonici, en Dictionnaire de Droit Canonique (Paris, 1942), III, col. 909-935.

Zuzek, Ivan, L'idée de Gasparri d'un Codex Ecclesiae Universae comme point de départ de la codification canonique orientale, en L'Année Canonique 38 (1996), pp. 53-74. 